\title{
Article \\ Experiment and Numerical Simulation on Grouting Reinforcement Parameters of Ultra-Shallow Buried Double-Arch Tunnel
}

\author{
Jianxiu Wang ${ }^{1,2,3, *}$, Ansheng Cao ${ }^{1} \mathbb{D}$, Zhao Wu ${ }^{1}$, Huanran Wang ${ }^{3}$, Xiaotian Liu ${ }^{1} \mathbb{D}$, Huboqiang Li $^{1}$ \\ and Yuanwei Sun ${ }^{1}$
}

1 Department of Geotechnical Engineering, College of Civil Engineering, Tongji University, Shanghai 200092, China; 2110410@tongji.edu.cn (A.C.); 1830161@tongji.edu.cn (Z.W.); 2012liuxiaotian@tongji.edu.cn (X.L.); 2030167@tongii.edu.cn (H.L.); 2132198@tongji.edu.cn (Y.S.)

2 Key Laboratory of Geotechnical and Underground Engineering of Ministry of Education, Tongji University, Shanghai 200092, China

3 Key Laboratory of Impact and Safety Engineering, Ministry of Education, Ningbo University, Ningbo 315211, China; wanghuanran@nbu.edu.cn

* Correspondence: wang_jianxiu@163.com; Tel.: +86-139-1618-5056 or +86-21-6598-3036; Fax: +86-21-6598-5210

Citation: Wang, J.; Cao, A.; Wu, Z.; Wang, H.; Liu, X.; Li, H.; Sun, Y. Experiment and Numerical Simulation on Grouting Reinforcement Parameters of Ultra-Shallow Buried Double-Arch Tunnel. Appl. Sci. 2021, 11, 10491. https://doi.org/10.3390/app112110491

Academic Editor: Daniel Dias

Received: 28 September 2021

Accepted: 4 November 2021

Published: 8 November 2021

Publisher's Note: MDPI stays neutral with regard to jurisdictional claims in published maps and institutional affiliations.

Copyright: (C) 2021 by the authors. Licensee MDPI, Basel, Switzerland. This article is an open access article distributed under the terms and conditions of the Creative Commons Attribution (CC BY) license (https:// creativecommons.org/licenses/by/ $4.0 /)$.

\begin{abstract}
For an ultra-shallow buried double-arch tunnel with a large cross-section, the arching effect is difficult to form in surrounding rock, and grouting method is often adopted to reinforce the surrounding rock. Hence, examining the grouting reinforcement parameters is of great significance for potential failure and collapse prevention. The land part of Haicang undersea tunnel was selected as a case study; laboratory experiments, theoretical analysis, and numerical simulation were performed to determine the grouting solid strength and grouting reinforcement parameters. The effects of different water-cement ratios on slurry fluidity, setting time, bleeding rate, and sample strength were studied by laboratory experiments. A method was proposed to determine the shear strength parameters of grouted surrounding rock through the grout water-cement ratio and the unconfined compressive strength of the rock mass. Numerical simulations were performed for grouting reinforcement layer thickness and the water-cement ratios. The deformation and stability law of tunnel surrounding rock and its influence on surrounding underground pipelines were obtained considering the spatial effect of tunnel excavation and grouting reinforcement. The reasonable selection range of grouting reinforcement parameters was proposed. The initial setting time and bleeding rate of cement slurry increased with the increasing water-cement ratio, while the viscosity of cement slurry and sample strength decreased with the increasing water-cement ratio. The shear strength parameters of grouted surrounding rock were determined by the water-cement ratio of grout and unconfined compressive strength of rock mass before grouting. When the thickness of grouting reinforcement layer $h=1.5 \mathrm{~m}$ and the water-cement ratio of grout was suggested $\eta=0.85$, the surface settlement, the deformation of the vault, and the deformation of the nearby pipeline all met the design. Moreover, the construction requirements were more economical. Research results can provide a reference for the selection of grouting reinforcement parameters for similar projects.
\end{abstract}

Keywords: double-arch tunnel; grouting reinforcement; water cement ratio; reinforcement layer thickness; laboratory experiment; numerical simulation

\section{Introduction}

Due to the influence and limitations of geographical location and surrounding environment, problems such as poor geological conditions, shallow burial depth, tight engineering land, complex surrounding environment, and strict control standards are common $[1,2]$. To overcome these challenges, double-arch tunnels are widely used in urban tunnels because of their advantages of convenient portal selection, smooth route, land conservation, beautiful section shape, and relatively small impact on the surrounding environment $[3,4]$. 
However, urban double-arch tunnels also have limitations, such as long construction period, high cost, various procedures, complex supporting structure, more intersection of excavation and supporting construction surfaces, and difficult quality control [5-7]. Additionally, with the construction of special underground projects involving environmental protection and surface cultural relics, an increasing number of ultra-shallow tunnels have been constructed. Hence, during the excavation and support process of an urban ultra-shallow buried double-arch tunnel with complex geological conditions, the stability of tunnel surrounding rock and the deformation control of surrounding underground pipelines have become issues that need special attention [8,9]. According to modern tunnel theory, the surrounding rock is the main body to bear the unloading stress caused by excavation. In the process of tunnel construction, effective technical means are necessary to adopt to maximize the self-supporting capacity of the surrounding rock. Such means improve the stability of the surrounding rock and tunnel structure, which can not only improve the safety of a project during construction, but also improves the quality and service life of the tunnel structure during operation $[10,11]$. To strengthen the bearing capacity of the rock mass and avoid possible risks in construction, various methods and measures are often adopted in the project, such as advance support, small pipe reinforcement, and grouting reinforcement to reinforce the surrounding rock [12-17]. Compared with other treatment methods, grouting reinforcement technology has the advantages of high efficiency, convenience, low cost, wide treatment range, and good reinforcement effect, especially in rock and soil with high fragmentation degree [18-20]. The principle of grouting reinforcement technology is to use cement slurry, water glass, cement mortar, chemical grout, and other materials to fill the voids of broken rock masses effectively to improve the compactness, integrity, tension, compression, shear, and creep of the rock mass, so as to maintain the stability of rock mass [21]. The strength and stability of grouted surrounding rock formed after grouting reinforcement of broken rock mass is not only an important index to evaluate the effect of grouting reinforcement, but also a key parameter to determine the deformation and the self-supporting capacity of the surrounding rock.

Extensive research has been carried out on grouting and reinforcement of surrounding rocks and remarkable results have been achieved. Zong et al. [22,23] found that the stiffness, roughness, peak shear strength, residual strength, and shear strength parameters of structural surface after grouting reinforcement were significantly improved. Niu et al. [14] studied the grouting diffusion law, splitting grouting reinforcement mechanisms and grouting reinforcement effects using 3D simulated grouting test system. The uniaxial compressive strength of filled soil after grouting increased by $186 \%$, the permeability coefficient decreased by 47 times, and the cohesion and internal friction angle increased by $45.3 \%$ and $44.9 \%$, respectively. Evdokimov et al. [24] compared and analyzed the shear strength parameters of fractured rock before and after grouting consolidation, and considered that grouting significantly increased the shear strength of fractured rock. Moosavi et al. [25] found that when the water-cement ratio was 0.4 and 0.5 , respectively, the peak and residual shear strength of grouted surrounding rock increased with the increasing normal stress. Taking the grouting reinforcement project of a large section cavern surrounding rock as the background, Cheng et al. [26] found a linear relationship between grouting volume and grouting pressure, hydraulic conductivity, and grouting time, and a square root relationship between slurry diffusion radius and grouting pressure, hydraulic conductivity, and grouting time through numerical simulations. On the basis of the tunnel crossing railway stations, Lu et al. [27] used ANSYS software to simulate and analyze the grouting reinforcement effect of tunnel surrounding rock according to the equivalent continuous medium theory. The results show that grouting reinforcement has a good effect on reducing surface settlement and horizontal convergence. Through grouting experiments on fully weathered granite, Yang et al. [28] studied the diffusion law of cement rule of different viscosity and the influence of grout viscosity on the reinforcement effect, and found that an increase of slurry viscosity strengthens compressive strength and shear strength. Liu et al. [29] found that the tensile strength of rock cracks increases with increasing grouting viscosity, 
but the overall tensile strength was low. Ma et al. [30] found that broken fine sandstone reinforced by compaction grouting slurry has obvious ductility, strong plasticity, and deformation resistance, and can remain stable in a large deformation range. Li et al. [31] took the compressive strength, deformation modulus and hydraulic conductivity of grouting reinforced rock mass as the evaluation index of grouting reinforcement effect, tested the grouting plus solid effect under different water-cement ratio and curing time, and found that slurry water-cement ratio has a significant impact on grouting reinforcement effect. Wang et al. [32] found that grouting reinforcement can effectively suppress the stress concentration at the crack tip, improve the integrity of the specimen, avoid the formation of stress redistribution, and enhance the integrity of the specimen.

Generally, the research on grouting reinforcement of surrounding rock has mostly studied the strength comparison and deformation analysis before and after grouting. However, only few studies have been conducted on the strength of grouted surrounding rock and how to determine grouting parameters of rock mass in engineering. With the land part of Haicang undersea tunnel as a background, laboratory experiments, literature analysis, and numerical simulation were performed to study the method and rationality of determining the grouting parameters of the surrounding rock of the ultra-shallow buried double-arch tunnel. The results can be referred by similar projects.

\section{Overview of the Engineering}

The double-arch tunnel of Haicang tunnel is located in Huli District, Xiamen City, Fujian Province, China. The tunnel is near to the Shigushan interchange. The entrance of the tunnel is located at the \#4 working shaft and the exit is located at the \#5 working shaft. The starting and ending mileage is BK $17+805-$ BK $18+045$, with a total length of $240 \mathrm{~m}$. The double-arch tunnel passes through Xinghu Road, a two-way six-lane urban expressway (Figure 1). Xinghu Road has dense traffic and heavy vehicles. Various municipal pipelines such as water supply, drainage, and power cables are densely covered under the road. They are all buried within $2.5 \mathrm{~m}$ below the ground and about $1.8-3.0 \mathrm{~m}$ above the top of the tunnel. Thus, determining the impact of tunnel excavation on nearby pipelines is necessary.

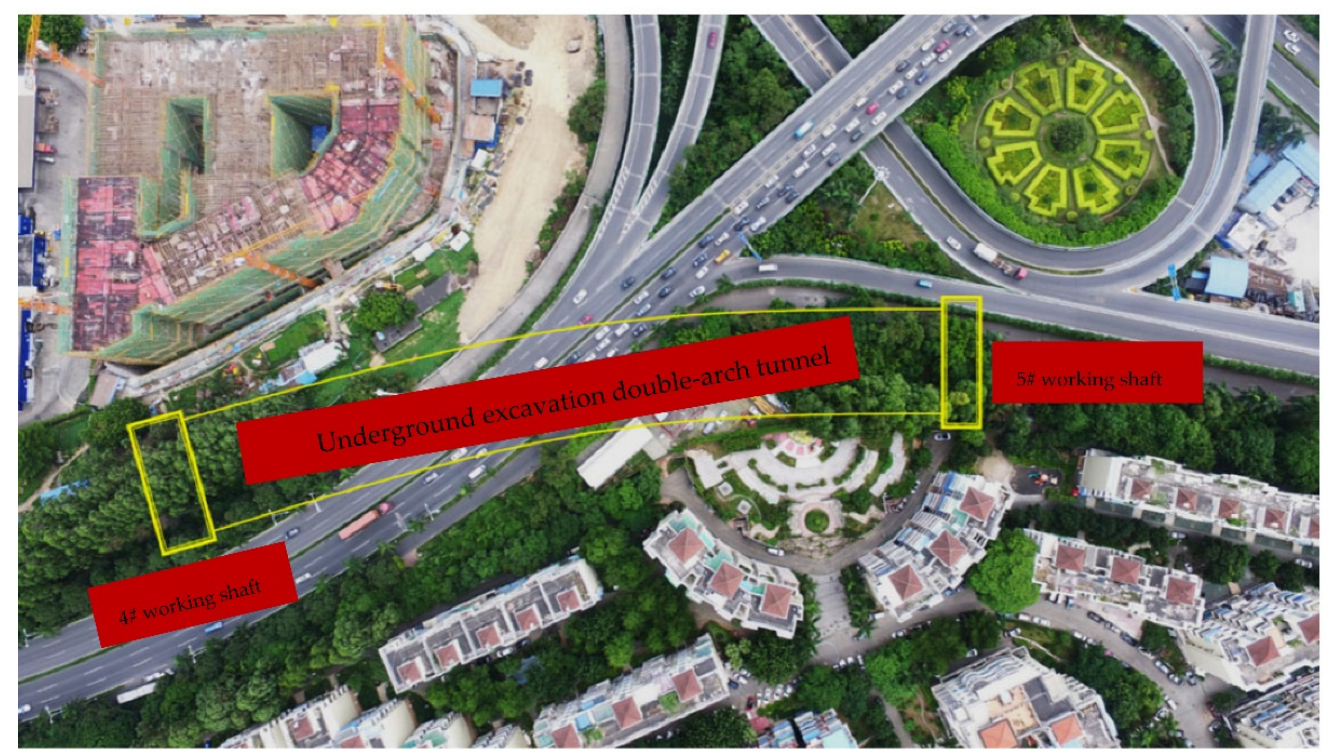

Figure 1. Schematic diagram of the plane position of the underground excavation double-arch tunnel.

The minimum buried depth of the main tunnel is about $5 \mathrm{~m}$ and the maximum buried depth is about $15.45 \mathrm{~m}$. The designed single tunnel has a headroom width of $14.60 \mathrm{~m}$ and a headroom height of $10.15 \mathrm{~m}$. The full cross-sectional area of the tunnel is $119.27 \mathrm{~m}^{2}$. Figure 2 shows the section of the double-arch tunnel. The tunnel is excavated by using the three heading excavation method. The side heading tunnel has a cross-sectional area of 
$26.7 \mathrm{~m}^{2}$, an excavation height of $6.44 \mathrm{~m}$, and an excavation width of $4.48 \mathrm{~m}$. The excavation section area of the middle heading tunnel is $49.85 \mathrm{~m}^{2}$, the excavation height is $8.1 \mathrm{~m}$, and the excavation width is $6.2 \mathrm{~m}$. The sequence of the three heading excavation method of the double-arch tunnel is to excavate the middle heading tunnel first, then the left heading tunnel, and finally the right heading tunnel. The construction step between heading tunnels is $20 \mathrm{~m}$. The step method is adopted for the heading excavation method and the upper step is excavated $3 \mathrm{~m}$ to $5 \mathrm{~m}$ ahead of the lower step.

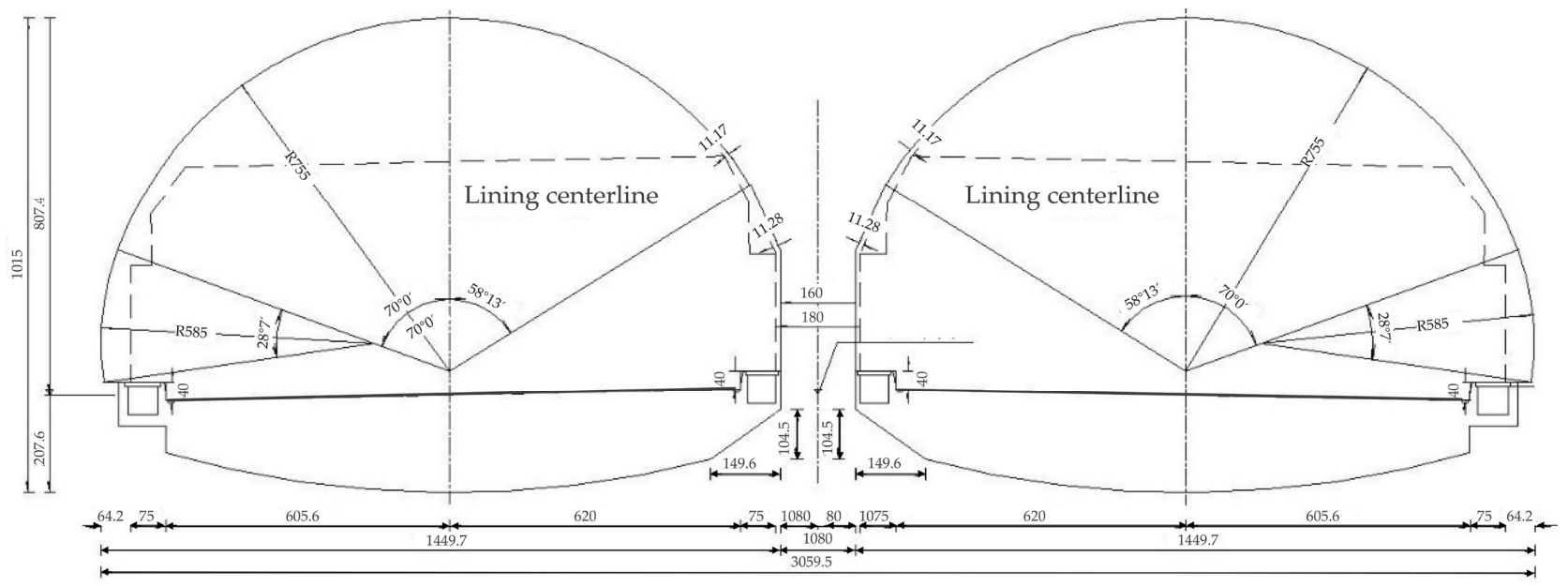

Figure 2. Cross-section of double-arch tunnel (unit: $\mathrm{cm}$ ).

\section{Laboratory Experiment}

\subsection{Grouting Ratio Experiment}

A single liquid cement slurry grouting method was adopted for the grouting ratio test, including the grouting method of mainly using cement materials, mixing water into slurry, and injecting single liquid into rock and soil layer. The raw material of the test slurry was 425 ordinary Portland cement. To study the variation law of cement slurry performance under different water-cement ratios, the water-cement ratios in the test were $0.4,0.6,0.8$, and 1. According to the standard for test methods of concrete physical and mechanical properties (GB/T50081-2019) [33], the cylinder sample was prepared. The corresponding proportion of cement and water were put into the mixing bucket and mixed manually. The mixture with the mold and tamp was filled manually. After tamping, the mold top cover was installed and the test piece was manually pressurized into a cylindrical specimen with a height of $100 \mathrm{~mm}$ and a diameter of $50 \mathrm{~mm}$. After standing for $30 \mathrm{~min}$ at room temperature, the specimen was demolded. The error of specimen height and diameter was controlled within $0.3 \mathrm{~mm}$, the maximum error of non-parallelism of both ends of the specimen was controlled within $0.05 \mathrm{~mm}$, the end surface was perpendicular to the axis, and the maximum error did not exceed $0.25 \mathrm{~mm}$. The samples were cured for 7 days around $20{ }^{\circ} \mathrm{C}$ under natural drying conditions. Figure 3 shows the sample. To provide a reasonable grouting ratio for tunnel grouting construction and to obtain a better grouting reinforcement effect, the grouting reinforcement effect was evaluated under different watercement ratios on the basis of the slurry fluidity, setting time, bleeding rate, and strength of the sample.

The fluidity of the slurry reflected the viscosity of the slurry. The greater the viscosity, the longer it took to inject into a certain position of the soil. The lower the viscosity, the stronger the fluidity of the slurry, and the grouting time can be shortened during the grouting process and the grouting efficiency can be improved. Figure 4 shows the fluidity test results of cement slurry. The viscosity of cement slurry decreased with the increasing watercement ratio. When the water-cement ratio increased from 0.6 to 1 , the initial viscosity of cement slurry decreased from $9.6 \mathrm{~s}$ to $8.48 \mathrm{~s}$, which is a decrease of $1.12 \mathrm{~s}$. At $30 \mathrm{~min}$, the viscosity decreased from $10.01 \mathrm{~s}$ to $8.48 \mathrm{~s}$, which is a decrease of $1.53 \mathrm{~s}$. The $60 \mathrm{~min}$ viscosity 
decreased from $10.8 \mathrm{~s}$ to $8.49 \mathrm{~s}$, which is a decrease of $2.31 \mathrm{~s}$. Additionally, the viscosity of cement slurry increased gradually under different water-cement ratio; the smaller the water-cement ratio was, the faster the viscosity increased. When the water-cement ratio was 1 , the viscosity remained basically unchanged with time.

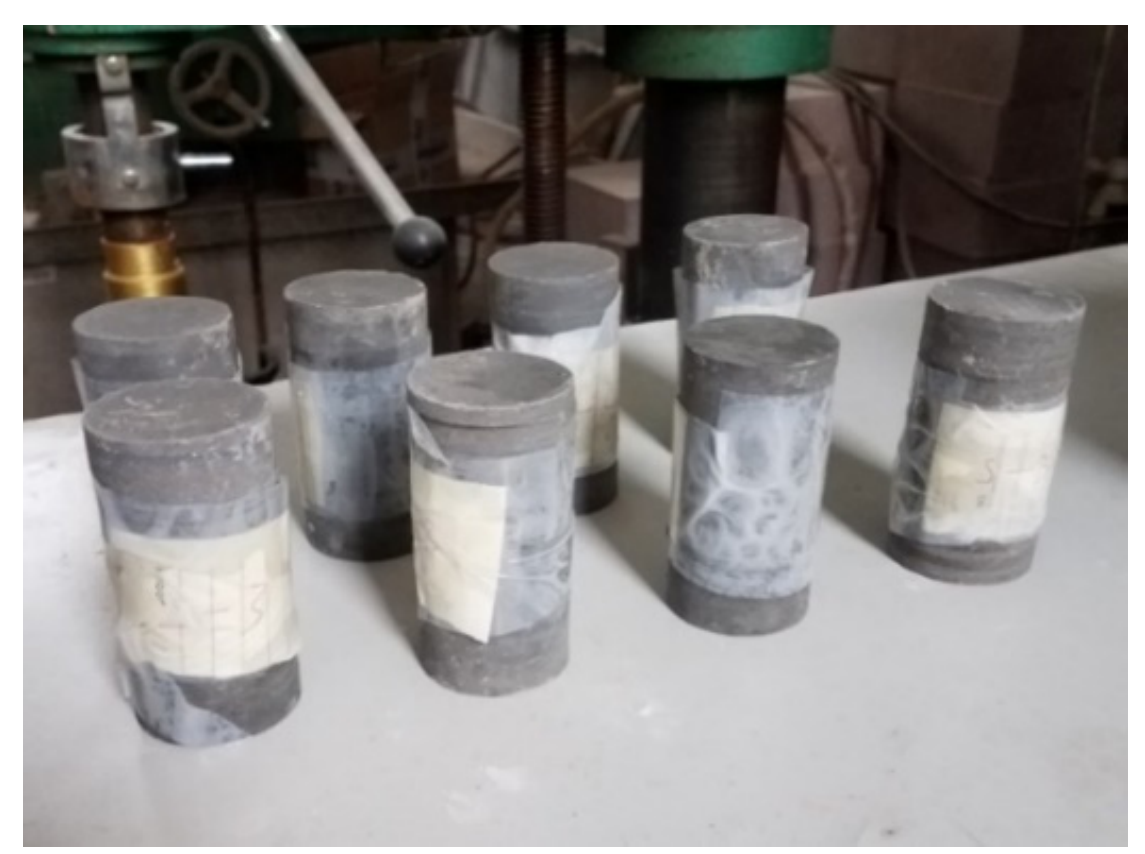

Figure 3. Test sample.

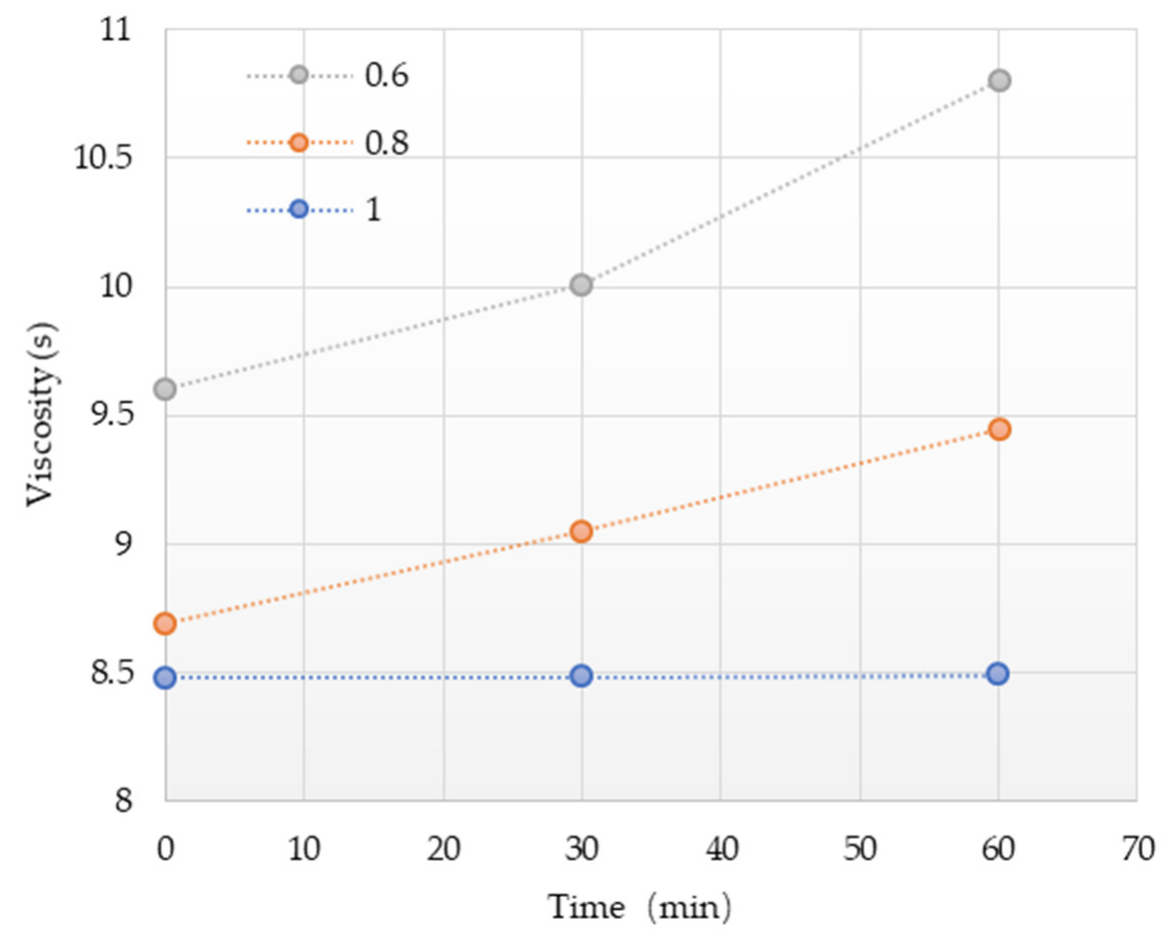

Figure 4. Fluidity test results of different water-cement ratios.

Figure 5 shows the relationship between water-cement ratio and initial setting time. The initial setting time of cement slurry basically increased linearly with the increasing water-cement ratio. When the water-cement ratio was 0.4 , the initial setting time of cement slurry was $318 \mathrm{~min}$, and when the water-cement ratio increased to 1.0, the initial setting 
time increased to $696 \mathrm{~min}$, an increase of about 1.2 times. According to the test results, the relationship between water-cement ratio and initial setting time of cement slurry was fitted, and the following was obtained:

$$
\mathrm{y}=630 \eta+39
$$

where y refers to the initial setting time of cement slurry ( $\mathrm{min}$ ) and $\eta$ refers to the watercement ratio of water slurry. The correlation coefficient $\mathrm{R}^{2}$ of the fitting result was 0.9997 , which shows that the fitting result was good.

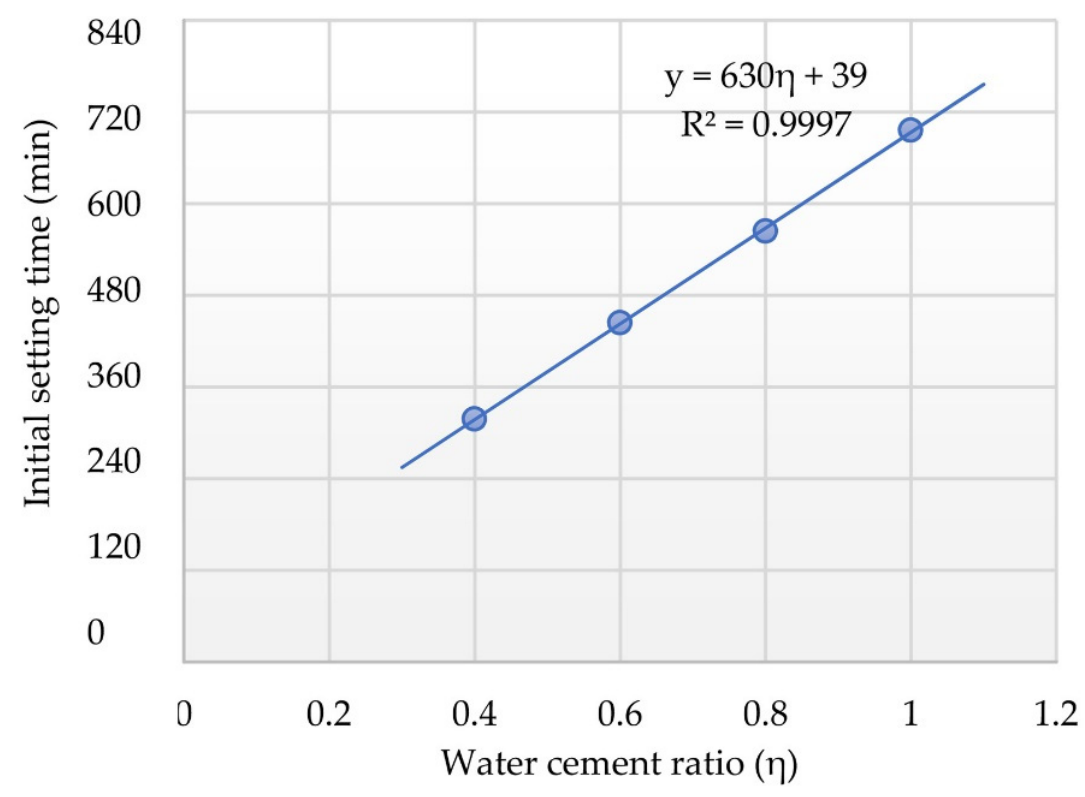

Figure 5. Relationship between water-cement ratio and initial setting time.

Cement and water were fully mixed to form a cement slurry. After standing for a period of time, a part of free water precipitated out of it. The phenomenon is called bleeding, which is related to the stability of the slurry. Figure 6 shows the bleeding rate of the cement slurry in the test. The bleeding rate of the slurries with different water cement ratios gradually increased to a certain value over time and then became stable, and the larger the water-cement ratio, the greater the bleeding rate of the slurry. When the water-cement ratio increased from 0.4 to 1 , the bleeding rate increased from $0.1 \%$ to $22.5 \%$ at $140 \mathrm{~min}$, an increase of $22.4 \%$, and the bleeding rate reached a stable level at about $50 \mathrm{~min}$. When the water-cement ratio was 0.4 , the bleeding rate was always maintained at $0.1 \%$, indicating that the sample almost did not separate water. When the water-cement ratio was 0.6 , the bleeding rate increased from $1 \%$ to $3.9 \%$ at $140 \mathrm{~min}$. When the water-cement ratio was 0.8 , the bleeding rate increased from $1.8 \%$ to $15 \%$ at $140 \mathrm{~min}$. When the water cement ratio was 1 , the bleeding rate increased from $3 \%$ to $22.5 \%$ at $140 \mathrm{~min}$, indicating that the sample had strong water separation.

Figure 7 shows the compressive strength of cement samples under different watercement ratios. The sample strength decreased linearly with the increasing water-cement ratio. When the water-cement ratio increased from 0.4 to 1.0, the strength decreased from 9.8 $\mathrm{MPa}$ to $3 \mathrm{MPa}$, which decreased by about 30.6\%. The fitting relationship between strength and water-cement ratio is shown below:

$$
f_{\mathrm{c}}=-11.089 \eta+14.313
$$

where $f_{\mathrm{c}}$ is the strength of the cement sample (MPa), and $\eta$ is the water-cement ratio. The correlation coefficient $\mathrm{R}^{2}$ of the fitting result was 0.993 . Thus, the fitting result was good. 


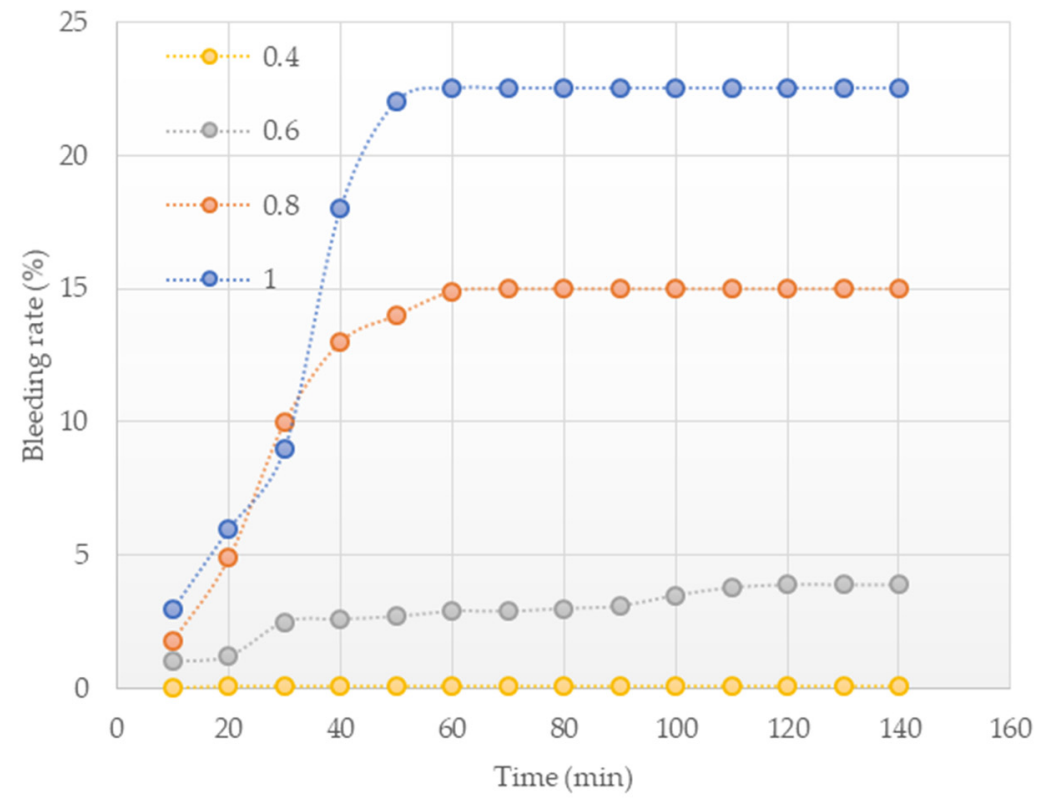

Figure 6. Bleeding rate of cement slurry with different water-cement ratios.

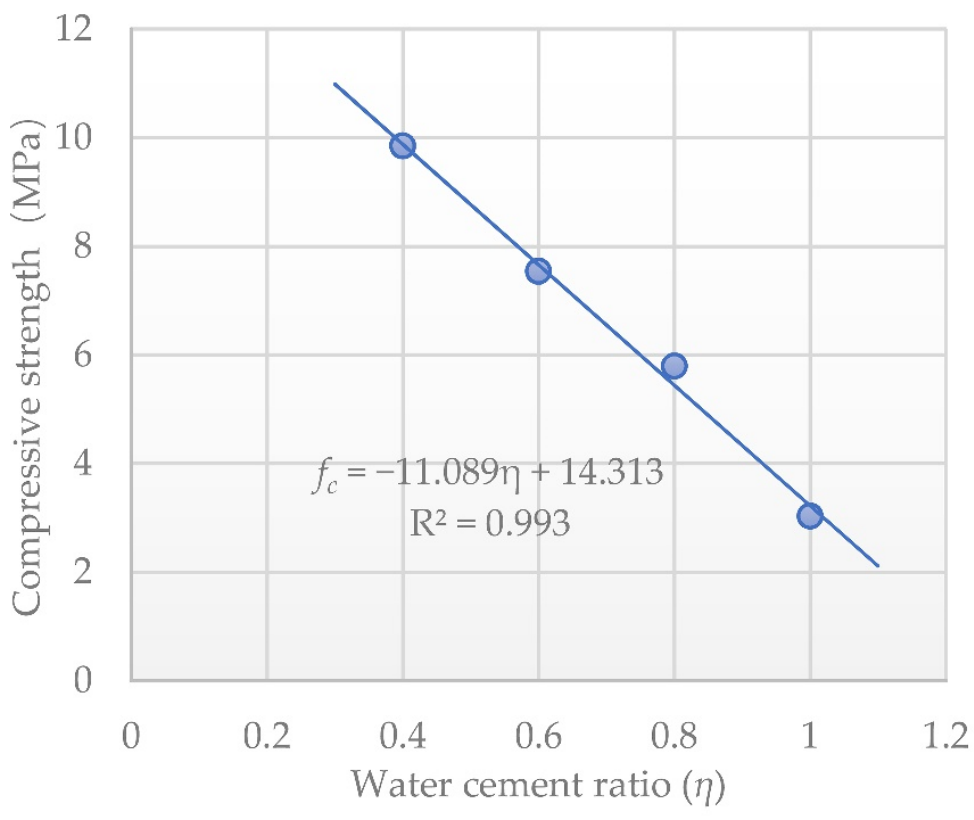

Figure 7. Compressive strength of cement sample with different water-cement ratios.

The water-cement ratio has different effects on the viscosity, bleeding rate, and initial setting time of cement slurry, and the reasonable water-cement ratio cannot be determined only by experiments - the influence of onsite conditions should be considered. To obtain a reasonable water-cement ratio, further numerical simulation research was performed.

\subsection{Grouted Surrounding Rock Strength}

The mechanical behavior of rock and soil conformed to the Mohr-Coulomb failure criterion, and the main grouting and solid strength parameters were the friction angle $\varphi$ and the cohesive force $\mathrm{c}$. The grouted surrounding rock strength has a great relationship with the strength of the rock mass before grouting, the strength of the grout stone body, grouting pressure, and time. When the grouting pressure and time met the specification requirements, the strength of rock and soil before grouting was the main influencing factor. The UCS of rock and soil before grouting, water-cement ratio, and strength of rock and 
soil after grouting reinforcement were obtained from references [34-41], combined with the relationship between rock mass UCS parameters and shear strength parameters (3) and (4), the friction angle $\varphi$ and cohesion c increase rate of grouted surrounding rock were obtained. Table 1 shows the statistical results.

$$
\begin{gathered}
\xi_{c o h}=0.95 \xi_{c}, \\
\xi_{f}=0.05 \xi_{c},
\end{gathered}
$$

where $\xi_{c o h}, \xi_{f}$ and $\xi_{c}$ are the increase rate of cohesive force $c(\%)$, friction angle $\varphi(\%)$ and UCS $(\%)$, respectively.

The data in Table 1 are plotted in Figures 8 and 9. The relationship between the UCS of rock and soil before grouting and the shear strength parameter increase rate of rock and soil after grouting were obtained by curve fitting when the water-cement ratio $\eta$ of the grout was 0.75 and 1.0. The distribution of the data has certain regularity. The cubic polynomial was used to fit the limited data corresponding to the slurry water-cement ratio $\eta=0.75$ and $\eta=1.0$, and the fitting correlation coefficients $R^{2}$ were 0.9738 and 0.8349 , respectively, indicating that the model fitting effect was good. The UCS, internal friction angle, and cohesion of the rock and soil before grouting in the construction area were determined according to geological survey data or laboratory experiments. The shear strength parameters of rock mass under different grouting reinforcement were calculated. According to the detailed survey report of Haicang Tunnel, the UCS of the surrounding rock before grouting within the tunnel excavation range was $0.108 \mathrm{MPa}$, the internal friction angle $\varphi=20^{\circ}$, and the cohesive force $c=0.06 \mathrm{MPa}$. Substituting the unconfined compressive strength into the fitting curve formulas of Figures 8 and 9, the shear strength increase rates of the rock and soil mass were obtained as $\xi_{\operatorname{coh}(\eta=0.75)}=596.5, \xi_{\mathrm{f}(\eta=0.75)}=31.4$, $\xi_{\operatorname{coh}(\eta=1.00)}=236.5$, and $\xi_{\mathrm{f}(\eta=1.00)}=12.4$. According to the shear strength increase rate, the internal friction angle $\varphi=20.28^{\circ}$ and the cohesion force $c=0.4179 \mathrm{MPa}$ when the water-cement ratio $\eta=0.75$. Similarly, the internal friction angle $\varphi=22.49^{\circ}$ and cohesion force $c=0.2019 \mathrm{MPa}$ when the water-cement ratio $\eta=1$.

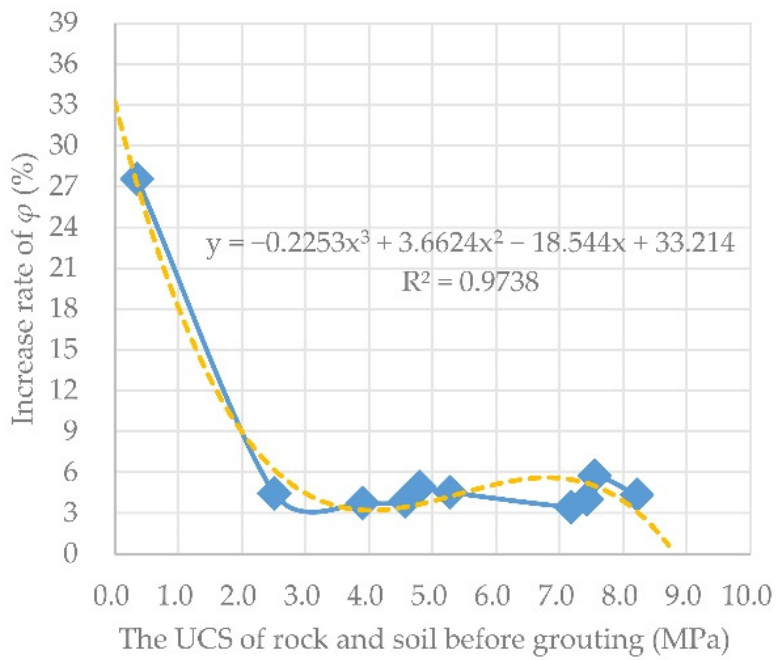

(a)

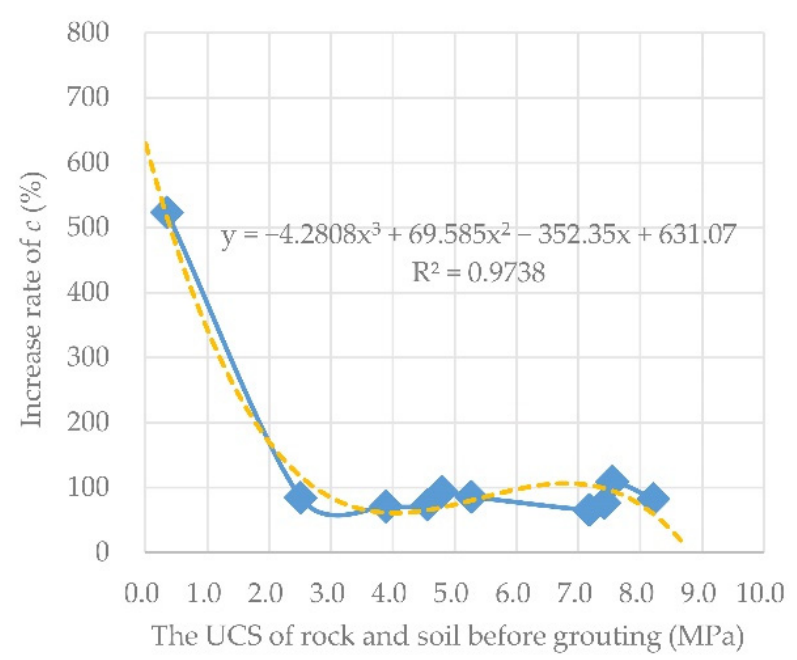

(b)

Figure 8. Relationship between the UCS of rock and soil before grouting and the shear strength parameter increase rate of rock and soil after grouting when water-cement ratio $\eta=0.75$ : (a) Relation between the increase rate of $\varphi$ and the UCS of rock and soil before grouting; (b) relation between the increase rate of $c$ and the UCS of rock and soil before grouting. 
Table 1. Compressive and shear strength of rock mass before and after grouting.

\begin{tabular}{|c|c|c|c|c|c|c|c|}
\hline Data Sources & Lithology & $\eta$ & $\begin{array}{l}\text { the UCS of Sample } \\
\text { before Grouting } \\
\text { (MPa) }\end{array}$ & $\begin{array}{l}\text { the UCS of Sample } \\
\text { after Grouting } \\
\text { (MPa) }\end{array}$ & $\begin{array}{c}\text { Increase } \\
\text { Rate of } \\
\xi_{c}(\%)\end{array}$ & $\begin{array}{c}\text { Increase } \\
\text { Rate of } \\
\xi_{f}(\%)\end{array}$ & $\begin{array}{c}\text { Increase } \\
\text { Rate of } \\
\xi_{c o h}(\%)\end{array}$ \\
\hline \multirow{3}{*}{$\begin{array}{c}\text { Experimental Research of Grouting } \\
\text { Reinforcement Mechanism for Broken Rock } \\
\text { Soil Mass as Heterogeneous Medium [34] }\end{array}$} & $\begin{array}{l}\text { Undisturbed soil and } \\
\text { fault gouge }\end{array}$ & 1.000 & 0.037 & 0.350 & 845.9 & 42.297 & 803.649 \\
\hline & $\begin{array}{l}\text { Undisturbed soil and } \\
\text { fault gouge }\end{array}$ & 1.000 & 0.084 & 0.398 & 373.8 & 18.690 & 355.119 \\
\hline & $\begin{array}{l}\text { Undisturbed soil and } \\
\text { fault gouge }\end{array}$ & 1.000 & 0.157 & 0.420 & 167.5 & 8.376 & 159.140 \\
\hline \multirow{8}{*}{$\begin{array}{l}\text { Mechanical characteristics of confined grouting } \\
\text { reinforcement for cracked rock mass [35] }\end{array}$} & Limestone & 0.750 & 7.176 & 12.140 & 69.2 & 3.459 & 65.716 \\
\hline & Limestone & 0.750 & 7.422 & 13.397 & 80.5 & 4.025 & 76.479 \\
\hline & Limestone & 0.750 & 8.214 & 15.360 & 87.0 & 4.350 & 82.648 \\
\hline & Limestone & 0.750 & 7.547 & 16.225 & 115.0 & 5.749 & 109.237 \\
\hline & Sandstone & 0.750 & 3.890 & 6.805 & 74.9 & 3.747 & 71.189 \\
\hline & Sandstone & 0.750 & 4.560 & 8.101 & 77.7 & 3.883 & 73.771 \\
\hline & Sandstone & 0.750 & 4.790 & 9.512 & 98.6 & 4.929 & 93.651 \\
\hline & Sandstone & 0.750 & 5.270 & 10.043 & 90.6 & 4.528 & 86.041 \\
\hline $\begin{array}{c}\text { Uniaxial Experiment Study on Mechanical } \\
\text { Properties of Reinforced Broken Rocks } \\
\text { Pre-and-post Grouting [36] }\end{array}$ & Red sandstone & 1.000 & 3.540 & 4.280 & 20.9 & 1.045 & 19.859 \\
\hline \multirow{2}{*}{$\begin{array}{c}\text { Study on the efficacy of grouting reinforcement } \\
\text { of slightly weathered rock masses at the Ertan } \\
\text { Arch Dam abutments [37] }\end{array}$} & $\begin{array}{l}\text { Weakly weathered } \\
\text { syenite }\end{array}$ & 1.000 & 6.430 & 7.770 & 20.8 & 1.042 & 19.798 \\
\hline & $\begin{array}{l}\text { Weakly weathered } \\
\text { syenite }\end{array}$ & 1.000 & 28.800 & 32.000 & 11.1 & 0.556 & 10.556 \\
\hline \multirow{4}{*}{$\begin{array}{l}\text { Reinforcement effect of cement grouting on } \\
\text { engineering rock mass [38] }\end{array}$} & Sandstone & 1.000 & 0.710 & 2.310 & 225.4 & 11.268 & 214.085 \\
\hline & Mudstone & 1.000 & 0.600 & 1.210 & 101.7 & 5.083 & 96.583 \\
\hline & Sandstone & 1.000 & 0.350 & 1.350 & 285.7 & 14.286 & 271.429 \\
\hline & Sandstone & 1.000 & 2.510 & 4.680 & 86.5 & 4.323 & 82.131 \\
\hline \multirow{2}{*}{$\begin{array}{l}\text { Study on the intrinsic model of broken } \\
\text { rockmass after grouting reinforcement [39] }\end{array}$} & Mudstone & 1.000 & 10.000 & 21.300 & 113.0 & 5.650 & 107.350 \\
\hline & Mudstone & 1.000 & 14.700 & 22.500 & 53.1 & 2.653 & 50.408 \\
\hline \multirow{2}{*}{$\begin{array}{l}\text { Test of grouting reinforcement of deep roadway } \\
\text { and control of its stability [40] }\end{array}$} & Sandstone & 1.000 & 34.300 & 55.300 & 61.2 & 3.061 & 58.163 \\
\hline & Malmstone & 1.000 & 0.100 & 1.220 & 1120.0 & 56.000 & 1064.000 \\
\hline \multirow{2}{*}{$\begin{array}{l}\text { Estimating strength of grouting reinforced } \\
\text { bodies in broken rock mass [41] }\end{array}$} & Sandstone & 1.000 & 34.300 & 55.300 & 61.2 & 3.061 & 58.163 \\
\hline & Malmstone & 1.000 & 0.100 & 1.220 & 1120.0 & 56.000 & 1064.000 \\
\hline
\end{tabular}




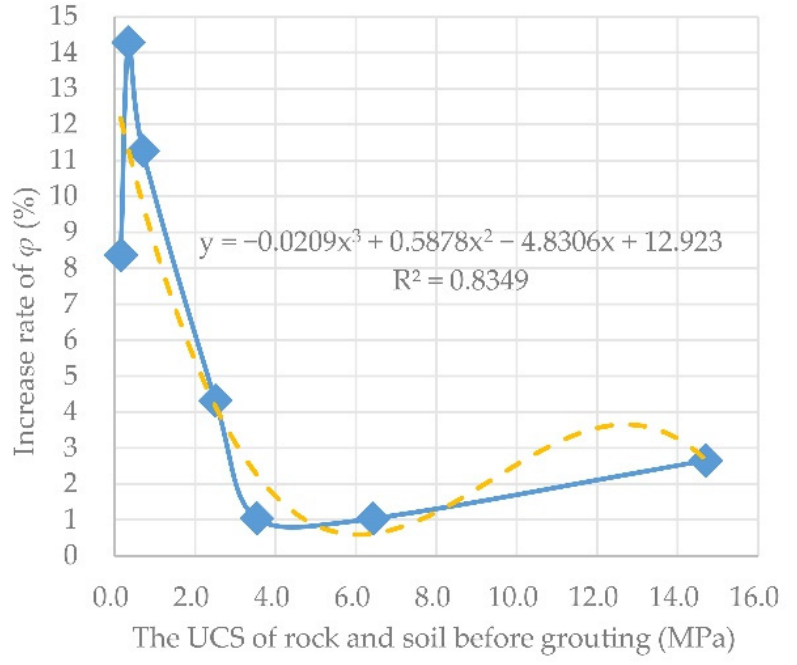

(a)

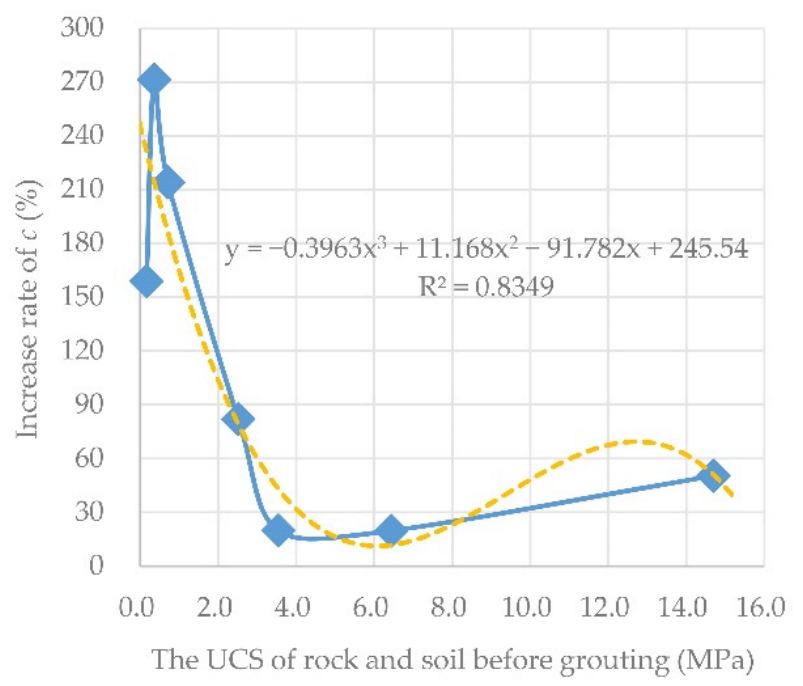

(b)

Figure 9. Relationship between the UCS of rock and soil before grouting and the shear strength parameter increase rate of rock and soil after grouting when water-cement ratio $\eta=1$ : (a) Relation between the increase rate of $\varphi$ and the UCS of rock and soil before grouting; (b) relation between the increase rate of $c$ and the UCS of rock and soil before grouting.

The influence of slurry water-cement ratio variation on the strength of grouted surrounding rock was analyzed. The deformation of the surrounding rock and the stability of the tunnel, the corresponding rock mass shear strength parameter when the water-cement ratio was $0.8,0.85,0.9$, and 0.95 were obtained by interpolation (Table 2).

Table 2. Shear strength parameters of grouted surrounding rock with different water-cement ratio.

\begin{tabular}{ccccccc}
\hline Water-Cement Ratio & $\mathbf{0 . 7 5}$ & $\mathbf{0 . 8 0}$ & $\mathbf{0 . 8 5}$ & $\mathbf{0 . 9 0}$ & $\mathbf{0 . 9 5}$ & $\mathbf{1 . 0 0}$ \\
\hline$\varphi\left({ }^{\circ}\right)$ & 26.3 & 25.5 & 24.8 & 24.0 & 23.3 & 22.5 \\
$c(\mathrm{MPa})$ & 0.42 & 0.38 & 0.33 & 0.29 & 0.24 & 0.20 \\
\hline
\end{tabular}

\section{Numerical Model}

\subsection{Finite Difference Model}

FLAC3D was used to study the grouting reinforcement effect of surrounding rock and its influence on surrounding rock deformation under different grouting parameters (thickness of reinforced layer and water-cement ratio of grout). The construction method, excavation sequence, and support of the form of the tunnel in the numerical simulation were the same as those in the actual project. The influence of surrounding rock deformation in horizontal and vertical directions on tunnel safety was obviously greater than that in the tunnel axis direction, and the influence of tunnel excavation on tunnel axial direction was not considered here. Therefore, a numerical model with a length of $120.00 \mathrm{~m}$ and a depth of $60 \mathrm{~m}$ was established for analysis. According to the actual situation, the stratum was divided into three parts, $0-4 \mathrm{~m}$ was miscellaneous fill, 4-26 m was fully weathered granite, and 26-60 m was fragmented strongly weathered granite, as shown in Figure 10. The supporting structure of the three heading tunnels in the model was built with shell elements, the lining of the main tunnel was established by solid elements, and the middle partition wall and two side partition walls were built with solid elements. The underground pipeline adopted a shell element, the diameter of the circular pipe was $0.4 \mathrm{~m}, 0.5 \mathrm{~m}$, and $0.6 \mathrm{~m}$ respectively, and the size of the square pipe was $0.45 \times 0.4 \mathrm{~m}$ and $1.2 \times 0.8 \mathrm{~m}$. According to the field conditions, the boundary conditions of the model were determined. The horizontal displacement of the left and right sides of the model was constrained, the 
horizontal and vertical displacement of the bottom surface of the model was constrained, and the top surface of the model was set as a free surface. The surrounding rock was set as an elastoplastic constitutive model and the mechanical behavior conformed to the Mohr-Coulomb failure criterion:

$$
\tau=c+\sigma \tan \varphi
$$

where $\tau$ is the shear strength (MPa), $\varphi$ is the internal friction angle $\left(^{\circ}\right), \sigma$ is the normal stress $(\mathrm{MPa})$, and $c$ is the cohesive force $(\mathrm{MPa})$. It shows that the shear strength of the rock mass is affected by the normal stress acting on the plane. The main reason for material failure is not the maximum shear stress, but the most dangerous combination of $\tau-\sigma$ on a certain plane.

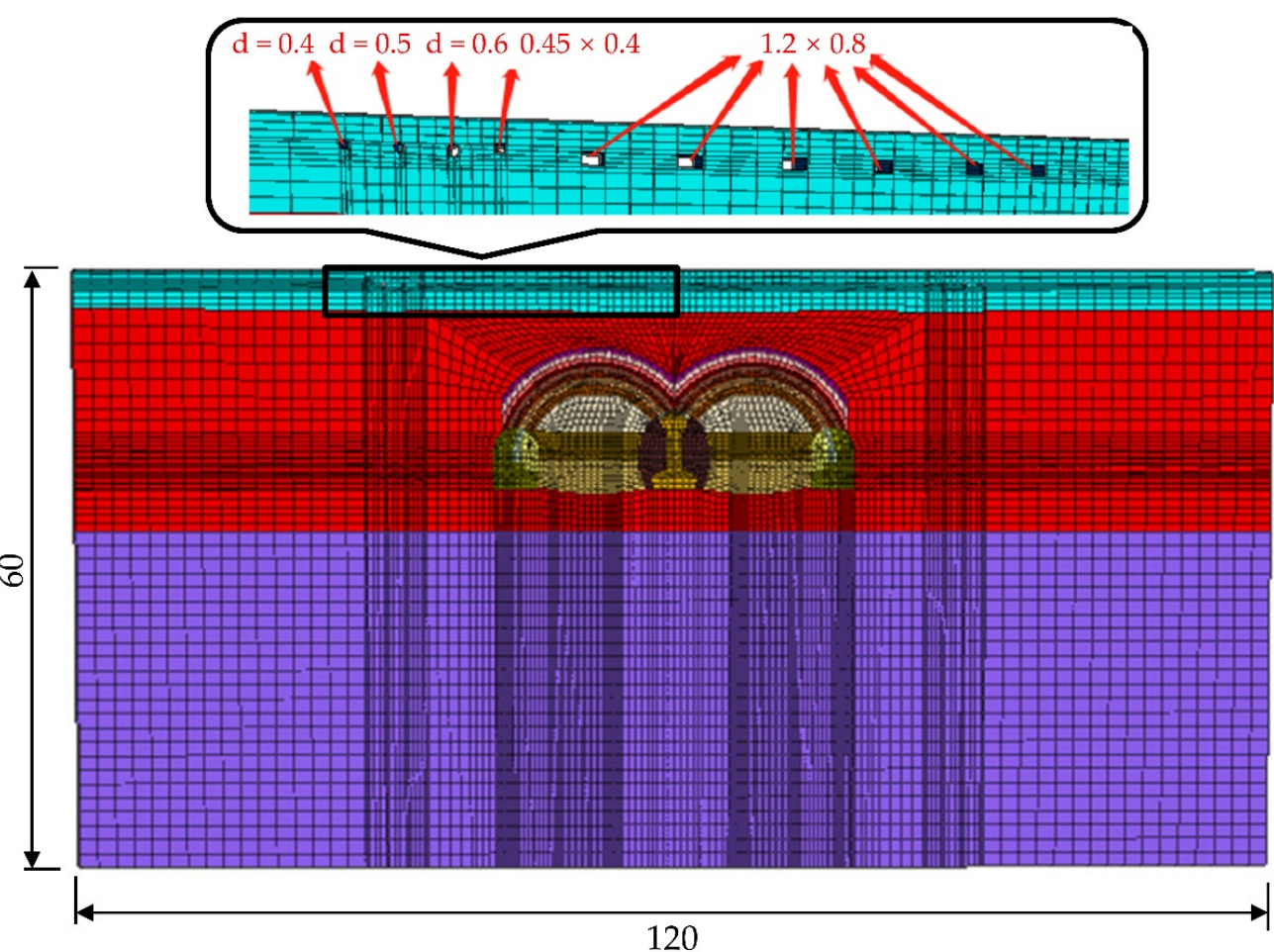

Figure 10. Numerical model of the double-arch tunnel (unit: m).

Table 3 shows the specific parameters of the surrounding rock. Considering the symmetry of the model, to simplify the calculation, only the left half of the model was analyzed in the numerical calculation.

\subsection{Simulation Conditions}

To study the influence of grouting reinforcement layer thickness $(\mathrm{h})$ on the grouting reinforcement effect, the surrounding rock of the tunnel vault was divided into five parts with a layer of $0.5 \mathrm{~m}$, as shown in Figure 11. Six working conditions were designed: non-grouting reinforcement, reinforcement of one layer, reinforcement of two layers, reinforcement of three layers, reinforcement of four layers, and reinforcement of five layers, that is $h=0$, $\mathrm{h}=0.5 \mathrm{~m}, \mathrm{~h}=1.0 \mathrm{~m}, \mathrm{~h}=1.5 \mathrm{~m}, \mathrm{~h}=2.0 \mathrm{~m}$, and $\mathrm{h}=2.5 \mathrm{~m}$. The strength parameters of the grouting reinforcement layer were set according to the parameters when the water-cement ratio $\eta=0.75$. To study the influence of grouted surrounding rock strength parameters on grouting reinforcement effect and surrounding rock stability, the following six working conditions were designed, namely water-cement ratio $\eta=0.75, \eta=0.80, \eta=0.85, \eta=0.90$, $\eta=0.95$, and $\eta=1.00$. The thickness of the grouting reinforcement layer was set as three layers, that is, $\mathrm{h}=1.5 \mathrm{~m}$. Table 3 shows the parameters of grouted surrounding rock strength. The whole simulation process first balanced the initial ground stress, then excavated the middle heading tunnel, and constructed the middle heading tunnel lining, excavated the 
left and right heading tunnels, constructed the left and right heading tunnel linings, and constructed the middle, left, and right partition walls. Then, the upper step of the left heading tunnel was reserved for core soil excavation, the upper step core soil excavation, the middle step excavation, and the lower step excavation.

Table 3. Model material parameters.

\begin{tabular}{|c|c|c|c|c|c|c|c|}
\hline Material & $\begin{array}{l}\text { Density } \\
\left(\mathrm{kg} / \mathrm{m}^{3}\right)\end{array}$ & $\begin{array}{l}\text { Elastic } \\
\text { Modulus } \\
\text { (MPa) }\end{array}$ & $\begin{array}{l}\text { Poisson's } \\
\text { Ratio }\end{array}$ & $\begin{array}{l}\text { Frictional } \\
\text { Angle }\left({ }^{\circ}\right)\end{array}$ & $\begin{array}{l}\text { Cohesive } \\
\text { Force (kPa) }\end{array}$ & $\begin{array}{c}\text { Coefficient of } \\
\text { Permeability } \\
\left(10^{-6} \mathrm{~m} \cdot \mathrm{s}\right)\end{array}$ & $\begin{array}{l}\text { Thickness } \\
\text { (m) }\end{array}$ \\
\hline Miscellaneous fill & 1900 & 10.76 & 0.32 & 19.4 & 26.8 & 52.52 & 4 \\
\hline $\begin{array}{c}\text { Completely weathered } \\
\text { granite }\end{array}$ & 1950 & 13.00 & 0.35 & 20.0 & 108.0 & 63.00 & 22 \\
\hline $\begin{array}{l}\text { Fragmentary strongly } \\
\text { weathered granite }\end{array}$ & 2300 & 10.72 & 0.3 & 30.5 & 56.5 & 82.00 & 24 \\
\hline Pipeline & 1400 & 2000 & 0.34 & - & - & - & 0.01 \\
\hline $\begin{array}{l}\text { The heading } \\
\text { tunnel lining }\end{array}$ & 2500 & $10,500.00$ & 0.25 & - & - & - & 0.3 \\
\hline $\begin{array}{l}\text { Inverted arch } \\
\text { initial support }\end{array}$ & 2600 & $34,000.00$ & 0.15 & - & - & - & 0.3 \\
\hline $\begin{array}{l}\text { Middle partition wall } \\
\text { and side wall }\end{array}$ & 2500 & $30,000.00$ & 0.20 & - & - & - & - \\
\hline $\begin{array}{l}\text { Initial support of the } \\
\text { first layer of arch }\end{array}$ & 2600 & $34,000.00$ & 0.15 & - & - & - & 0.3 \\
\hline $\begin{array}{l}\text { Initial support of the } \\
\text { second layer of arch }\end{array}$ & 2550 & $32,000.00$ & 0.15 & - & - & - & 0.22 \\
\hline
\end{tabular}

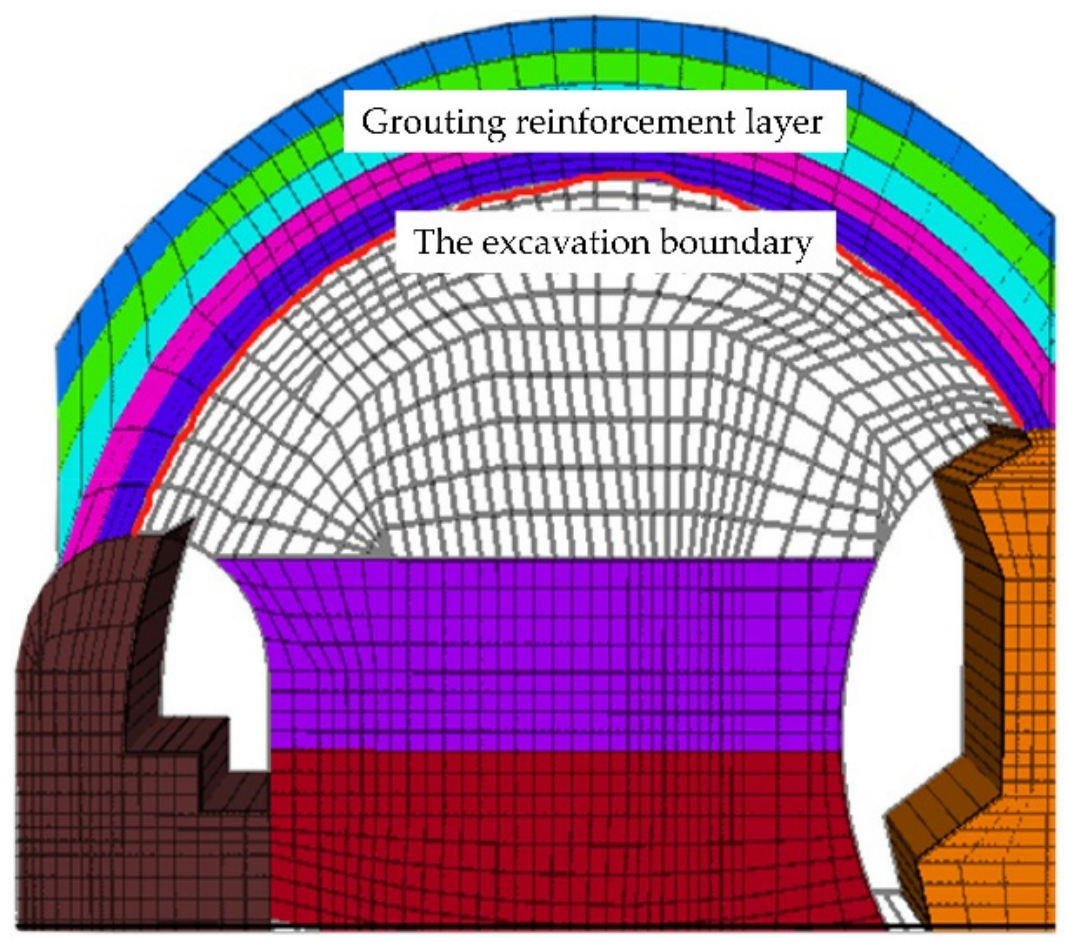

Figure 11. Grouting reinforcement layer. 


\subsection{Verification of Numerical Model}

To ensure the authenticity and effectiveness of the simulation results, the validity of the numerical model was verified. The accuracy of the numerical calculation model was verified by comparing the settlement of the tunnel vault obtained from field monitoring and numerical simulation. In the field construction, the thickness of the grouting reinforcement layer was $1.5 \mathrm{~m}$ and the slurry water-cement ratio was 0.85 . The settlement of the left tunnel vault at different distances from the tunnel portal after excavation was obtained through monitoring, as shown in Figure 12. During construction, the tunnel portal was reinforced, so the settlement of the tunnel vault near the portal was small. Additionally, there were differences in the mechanical properties of surrounding rocks at different positions from the portal, so the vault settlement was also different, and the variation range of vault settlement was 5.1-24.5 mm. In the numerical simulation, when the thickness of the grouting reinforcement layer was $1.5 \mathrm{~m}$ and the slurry water-cement ratio was 0.85 , the settlement of the left tunnel vault was $25.8 \mathrm{~mm}$. The tunnel vault settlement obtained by field monitoring and numerical simulation was relatively close. The accuracy of the numerical model was reliable.

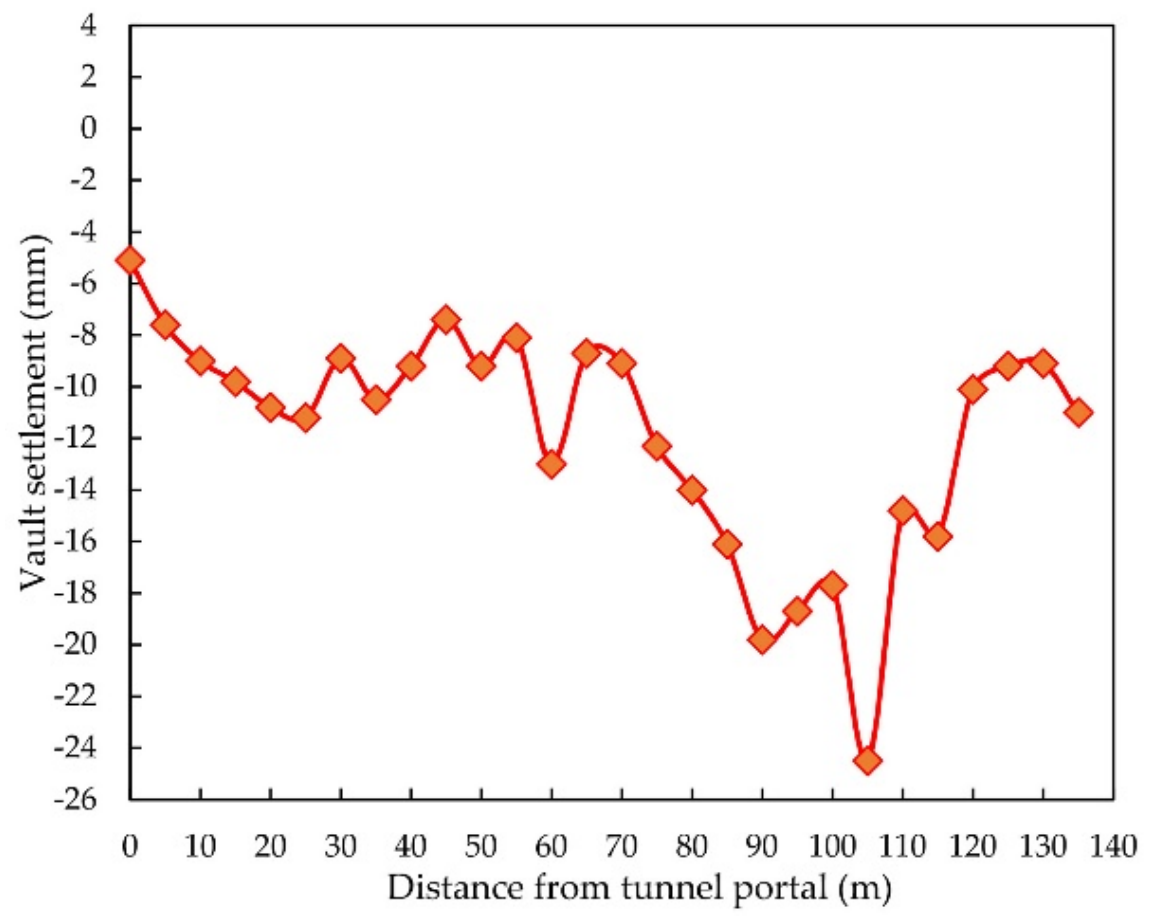

Figure 12. Settlement of the left tunnel vault in the field.

\subsection{Influence of Grouting Reinforcement Layer Thickness}

The thickness of the grouting reinforcement layer was an important factor to determine the grouting reinforcement effect. The greater the thickness of the reinforcement layer, the better the reinforcement effect and the higher the stability of the surrounding rock. However, with the increase of reinforcement layer thickness, larger grouting pipe, higher grouting pressure, and longer grouting time were needed. Therefore, if the target design was improper, defects may be induced such as material waste, cost rise, construction delay, which would seriously affect the economy, environmental protection, and rationality of the project.

\subsubsection{Ground Settlement Analysis}

Figure 12 shows the settlement curves of various monitoring points on the ground when the grouting reinforcement layer thickness was $h=0 \mathrm{~m}, 0.5 \mathrm{~m}, 1.0 \mathrm{~m}, 1.5 \mathrm{~m}, 2.0 \mathrm{~m}$, and $2.5 \mathrm{~m}$ are shown in Figure 13. The position corresponding to $\mathrm{x}=0$ was the central axis of 
the left tunnel, the negative direction was away from the tunnel, and the positive direction was close to the right tunnel. The ground settlement curve was roughly parabolic. When $\mathrm{h}=0 \mathrm{~m}, 0.5 \mathrm{~m}$, and $1.0 \mathrm{~m}$, the maximum ground settlement was located on the ground directly above the central axis of the left tunnel. When $h=1.5 \mathrm{~m}, 2.0 \mathrm{~m}$, and $2.5 \mathrm{~m}$, the maximum ground settlement was located on the right ground $4 \mathrm{~m}$ away from the central axis of the left tunnel. With the increase of the grouting reinforcement layer thickness, the location of the maximum ground settlement gradually shifted from the ground center point corresponding to the central axis of the left tunnel to the right tunnel. Comparing the ground settlement curve when the reinforcement layer thickness was $h=0.5 \mathrm{~m}$ and $\mathrm{h}=1.0 \mathrm{~m}$, the maximum settlement changed greatly, indicating that the reinforcement effect changed greatly there.

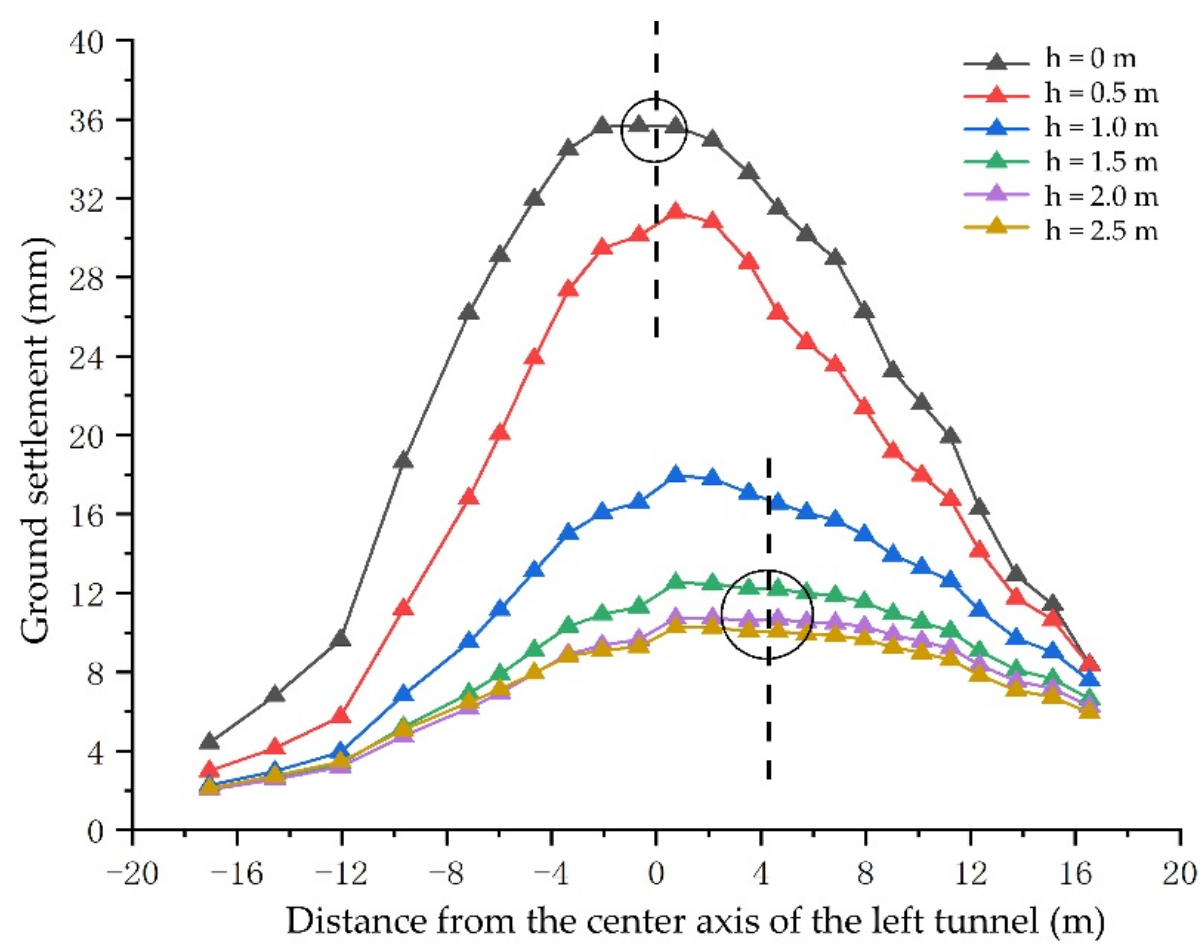

Figure 13. Ground settlement at monitoring points.

Figure 14 shows the relationship between the maximum ground settlement and the grouting reinforcement layer thickness. When the thickness of the grouting reinforcement layer was $\mathrm{h}=0 \mathrm{~m}, 0.5 \mathrm{~m}, 1.0 \mathrm{~m}, 1.5 \mathrm{~m}, 2.0 \mathrm{~m}$, and $2.5 \mathrm{~m}$, the corresponding maximum ground settlement was $35.7 \mathrm{~mm}, 31.3 \mathrm{~mm}, 18.0 \mathrm{~mm}, 12.5 \mathrm{~mm}, 10.7 \mathrm{~mm}$, and $10.3 \mathrm{~mm}$ respectively, and the variation range of the maximum settlement was $4.4 \mathrm{~mm}, 13.3 \mathrm{~mm}$, $5.5 \mathrm{~mm}, 1.8 \mathrm{~mm}$, and $0.4 \mathrm{~mm}$ respectively. The maximum variation range of settlement was the largest between $\mathrm{h}=0.5 \mathrm{~m}$ and $\mathrm{h}=1.0 \mathrm{~m}$, indicating that the reinforcement effect was significant when the reinforcement layer thickness h changed from $0.5 \mathrm{~m}$ to $1.0 \mathrm{~m}$. With the increase of grouting reinforcement layer thickness, the maximum variation range of settlement decreased rapidly. When the grouting reinforcement layer thickness changed from $2 \mathrm{~m}$ to $2.5 \mathrm{~m}$, the maximum variation range of surface settlement was only $0.4 \mathrm{~mm}$ and the reinforcement effect obtained was not obvious. Grouting reinforcement has a great impact on the ground settlement. The greater the thickness of the reinforcement layer, the better the reinforcement effect. Considering the maximum ground settlement and its variation range, when the thickness of the grouting reinforcement layer was $\mathrm{h}=1.0 \mathrm{~m}$ and $\mathrm{h}=1.5 \mathrm{~m}$, the maximum ground settlement caused by excavation was smaller and the reduction range was large, the reinforcement effect obtained was better and the benefit was higher. 


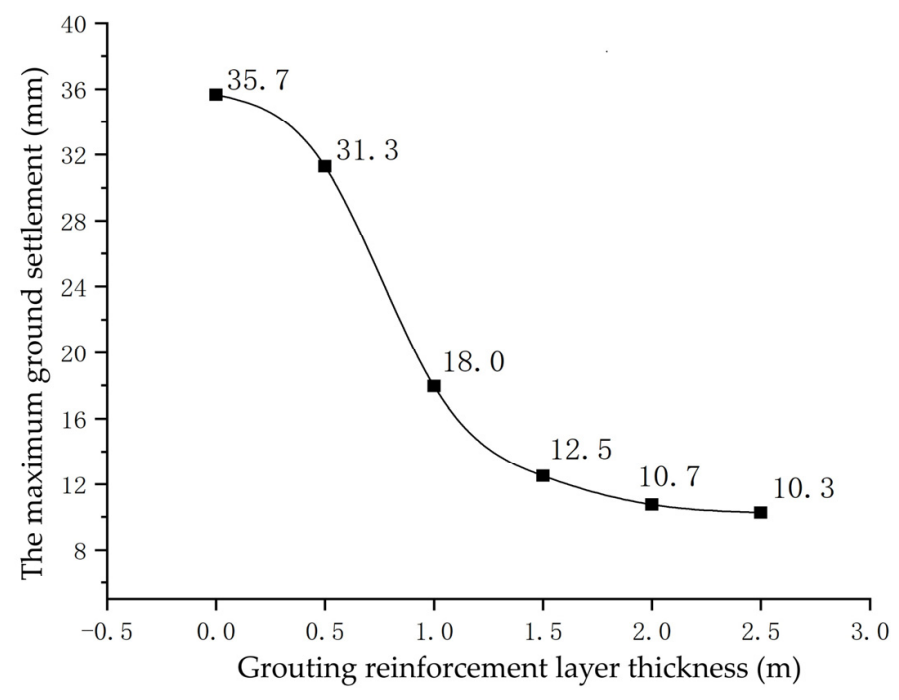

Figure 14. Relationship between the maximum ground settlement and the grouting reinforcement layer thickness.

\subsubsection{Vault Displacement Analysis}

Figure 15 shows the displacement of seven monitoring points near the vault of the left tunnel. Monitoring point 4 was the center of the vault, monitoring points 1-3 were on the left side of the center of the vault, and monitoring points 5-7 were on the right side of the vault. The closer to the vault, the greater the displacement. When $\mathrm{h}=0 \mathrm{~m}, 0.5 \mathrm{~m}$, and $1.0 \mathrm{~m}$, the maximum displacement was at monitoring point 3 . When $\mathrm{h}=1.5 \mathrm{~m}, 2.0 \mathrm{~m}$, and $2.5 \mathrm{~m}$, the maximum displacement was at the center of the vault. With the increasing grouting reinforcement layer thickness, the area with the maximum displacement gradually shifted to the center of the vault.

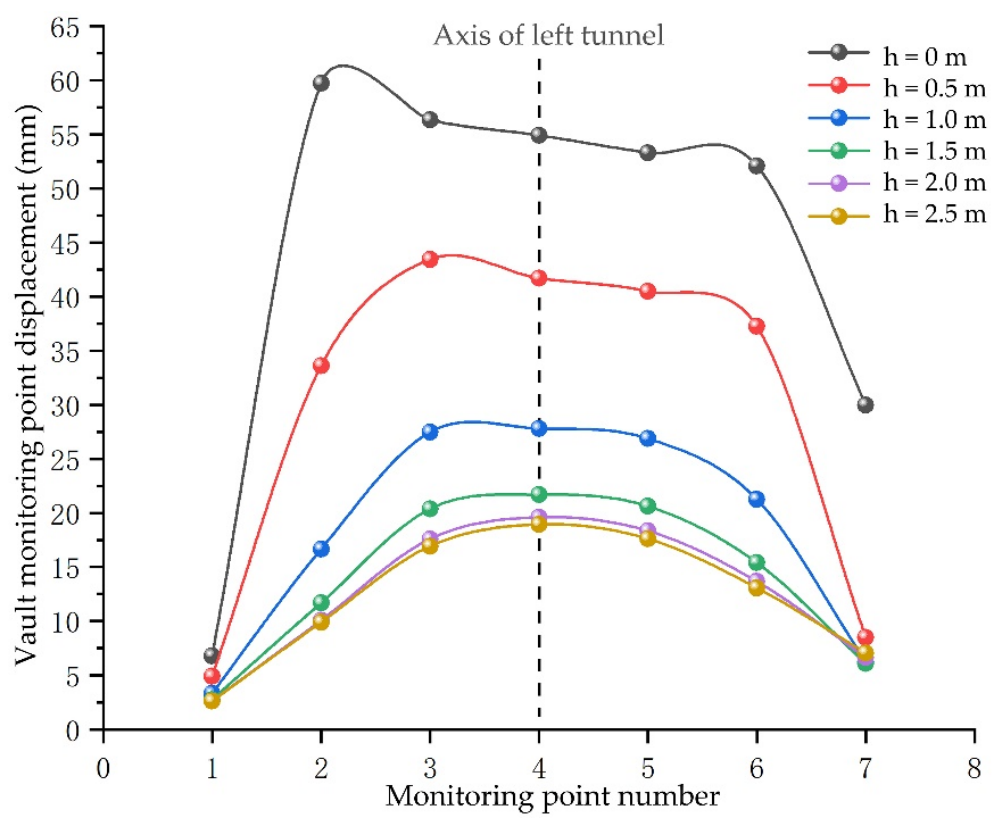

Figure 15. Displacement of 7 monitoring points near the vault of the left tunnel.

Figure 16 shows the relationship between the maximum displacement of the vault monitoring points and grouting reinforcement layer thickness. When the thickness of the reinforcement layer was $h=0 \mathrm{~m}, 0.5 \mathrm{~m}, 1.0 \mathrm{~m}, 1.5 \mathrm{~m}, 2.0 \mathrm{~m}$, and $2.5 \mathrm{~m}$, the maximum displacement of the vault was $59.7 \mathrm{~mm}, 43.4 \mathrm{~mm}, 27.8 \mathrm{~mm}, 21.7 \mathrm{~mm}, 19.6 \mathrm{~mm}$, and $18.9 \mathrm{~mm}$, respectively. Compared with the simulation result of the previous reinforcement layer, 
the variation range of the maximum displacement of the vault was $16.3 \mathrm{~mm}, 15.6 \mathrm{~mm}$, $6.1 \mathrm{~mm}, 2.1 \mathrm{~mm}$, and $0.7 \mathrm{~mm}$. With the increase of grouting reinforcement layer thickness, the maximum displacement of the vault decreased, and the reduction amplitude also decreased. When the thickness of the reinforcement layer was small $(\mathrm{h}=0 \mathrm{~m}, 0.5 \mathrm{~m}, 1.0 \mathrm{~m})$, increasing the thickness of the reinforcement layer obtained an obvious reinforcement effect. However, when the thickness of the reinforcement layer was large $(\mathrm{h}=1.5 \mathrm{~m}, 2.0 \mathrm{~m}, 2.5 \mathrm{~m})$, the reinforcement was not obvious by increasing the thickness of the reinforcement layer. Considering the maximum vault displacement and its variation range, when the thickness of the grouting reinforcement layer was $h=1.5 \mathrm{~m}$, the maximum vault displacement was small and the reduction was large. The reinforcement effect was better and the benefits were higher.

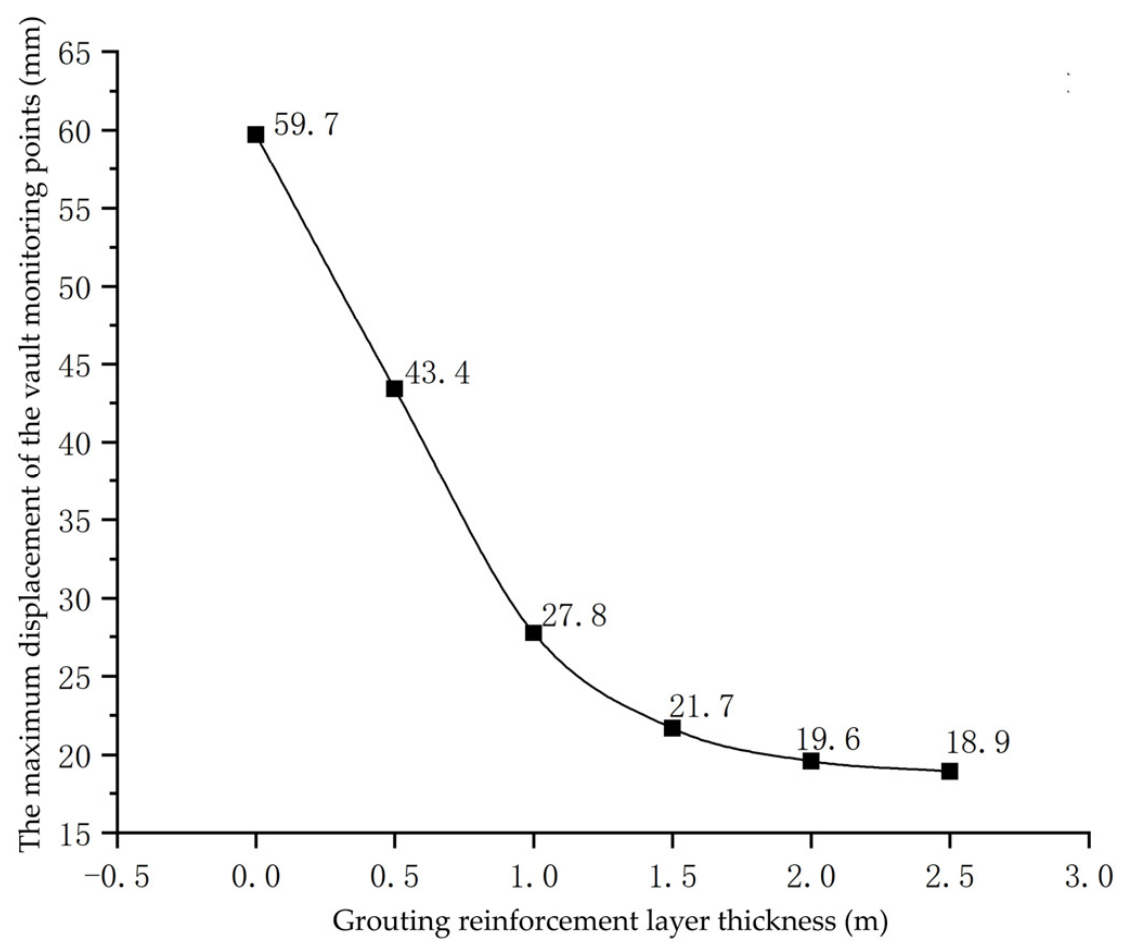

Figure 16. Relationship between the maximum displacement of the vault and grouting reinforcement layer thickness.

\subsubsection{Surrounding Rock Plastic Zone}

The plastic zone referred to the yield zone where plastic deformation occurred. According to different yield forms, plastic deformation can be divided into the shear plastic zone and tensile plastic zone. The surrounding rock in the plastic zone has poor mechanical properties, and plastic deformation that cannot be recovered by itself occurred, and strength failure was even a risk when it exceeded its bearing capacity. The area of the plastic zone was a key parameter that reflected the damage degree of the surrounding rock. The larger the area of the plastic zone, the higher the damage degree of the surrounding rock. Table 4 shows the area of shear and tensile plastic zone of surrounding rock under different grouting reinforcement layer thicknesses. With the increase of the grouting reinforcement layer thicknesses, the area of the shear plastic zone first decreased and then increased slightly. When the thickness of reinforcement layer $\mathrm{h}=1.5 \mathrm{~m}$, the area of the shear plastic zone reached the minimum $126.17 \mathrm{~m}^{2}$. The area of the tensile plastic zone basically decreased with the increase of the grouting reinforcement layer thicknesses. The singularity was that when $\mathrm{h}=1.5 \mathrm{~m}$, the area of the tensile plastic zone was $22.41 \mathrm{~m}^{2}$, which was smaller than that obtained in the two adjacent working conditions. The surrounding rock of the tunnel could fully exert its self-supporting capacity in the case of grouting reinforcement layer thickness $h=1.5 \mathrm{~m}$, the possibility of yield failure was small, the grouting reinforcement 
effect of the surrounding rock was better, and the gains obtained were higher. In Table 4, the ratio of the shear plastic area of grouted surrounding rock to the shear plastic area of surrounding rock without grouting $(h=0)$ was $\omega_{1}$. The ratio of the area of grouted surrounding rock tensile plastic zone to the area of surrounding rock tensile plastic zone without grouting $(\mathrm{h}=0)$ was $\omega_{2}$. When the reinforcement layer thickness was $\mathrm{h}=1.5 \mathrm{~m}$, $\omega_{1}$ and $\omega_{2}$ were 0.33 and 0.08 , respectively. Compared with the reinforcement condition without grouting, the areas of the shear plastic zone and tensile plastic zone were reduced by $67 \%$ and $92 \%$, respectively.

Table 4. Shear and tensile plastic zone area of surrounding rock under different grouting reinforcement layer thickness.

\begin{tabular}{ccccccc}
\hline Grouting Reinforcement Layer Thickness & $\mathbf{h}=\mathbf{0}$ & $\mathbf{h}=\mathbf{0 . 5} \mathbf{m}$ & $\mathbf{h}=\mathbf{1 . 0} \mathbf{m}$ & $\mathbf{h}=\mathbf{1 . 5} \mathbf{m}$ & $\mathbf{h}=\mathbf{2 . 0} \mathbf{~ m}$ & $\mathbf{h}=\mathbf{2 . 5} \mathbf{~ m}$ \\
\hline Shear plastic zone area $\left(\mathrm{m}^{2}\right)$ & 384.78 & 354.35 & 182.15 & 126.17 & 137.64 & 142.73 \\
$\omega_{1}$ & 1 & 0.92 & 0.47 & 0.33 & 0.36 & 0.37 \\
Tensile plastic zone area $\left(\mathrm{m}^{2}\right)$ & 286.16 & 252.30 & 61.73 & 22.41 & 24.37 & 17.98 \\
$\omega_{2}$ & 1 & 0.88 & 0.22 & 0.08 & 0.09 & 0.06 \\
\hline
\end{tabular}

\subsubsection{Pipeline Deformation}

Figure 17 shows the deformation of the pipeline; the abscissa was the distance from the center line of the middle partition wall and the dotted line was the position of the central axis of the left tunnel. With the increasing distance from the center line of the middle partition wall, the pipeline deformation first increased and then decreased. The pipeline deformation reached the maximum near the central axis of the left tunnel. When the distance from the center line of the middle partition wall was greater than $25 \mathrm{~m}$, the pipeline deformation was small and the deformation was basically stable. The thickness of the reinforcement layer had an obvious influence on the deformation of the pipeline. With the increase of the thickness of the reinforcement layer, the deformation of the pipeline was smaller and tends to stabilize faster.

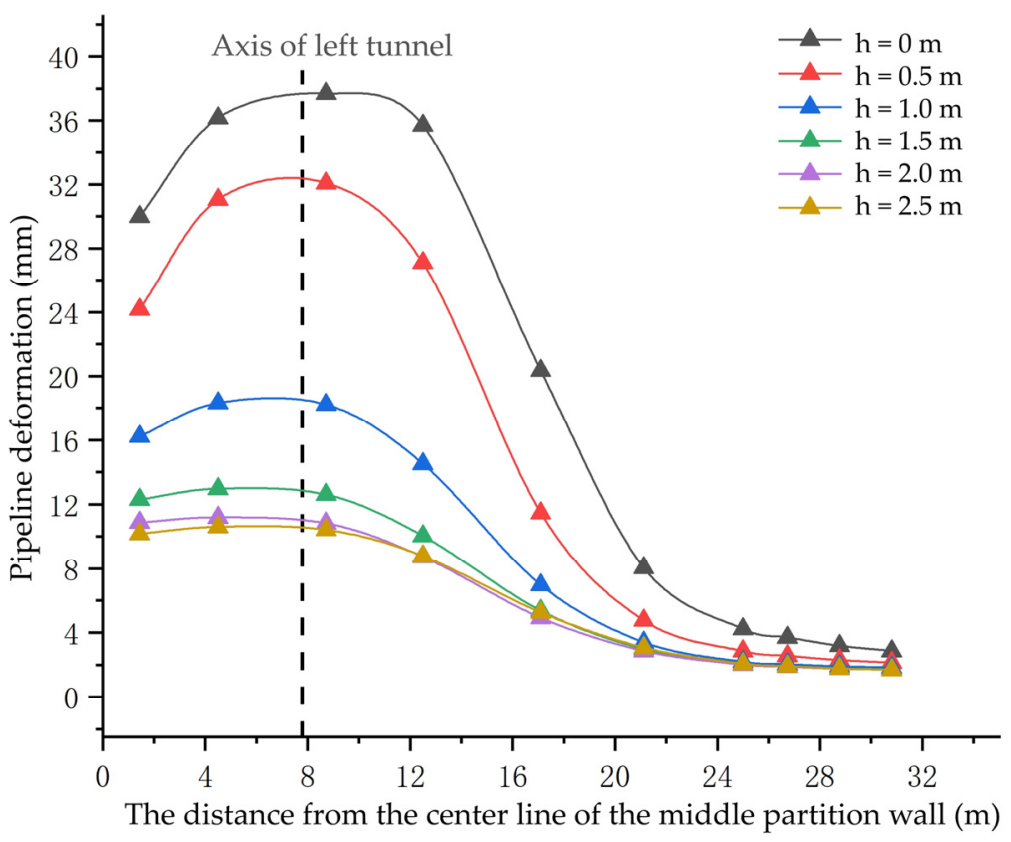

Figure 17. Pipeline deformation.

Figure 18 shows the relationship between the maximum displacement of the pipeline and the thickness of the grouting reinforcement layer. When the reinforcement layer thickness was $\mathrm{h}=0 \mathrm{~m}, 0.5 \mathrm{~m}, 1.0 \mathrm{~m}, 1.5 \mathrm{~m}, 2.0 \mathrm{~m}$, and $2.5 \mathrm{~m}$, the maximum displacement of the pipeline was $37.7 \mathrm{~mm}, 32.1 \mathrm{~mm}, 18.3 \mathrm{~mm}, 13.0 \mathrm{~mm}, 11.2 \mathrm{~mm}$, and $10.6 \mathrm{~mm}$, respectively. 
Compared with the results of the previous reinforcement layer thickness condition, the amplitude of the maximum displacement of the pipeline was $5.6 \mathrm{~mm}, 13.8 \mathrm{~mm}, 5.3 \mathrm{~mm}$, $1.8 \mathrm{~mm}$, and $0.6 \mathrm{~mm}$. With the increasing grouting reinforcement layer thickness, the maximum displacement of the pipeline gradually decreased and the variation amplitude first increased and then decreased. When $\mathrm{h}=1.0 \mathrm{~m}$ and $\mathrm{h}=1.5 \mathrm{~m}$, the maximum displacement of the pipeline was small (less than $20 \mathrm{~mm}$ ) and the variation amplitude was large, indicating that the effect of grouting reinforcement was good.

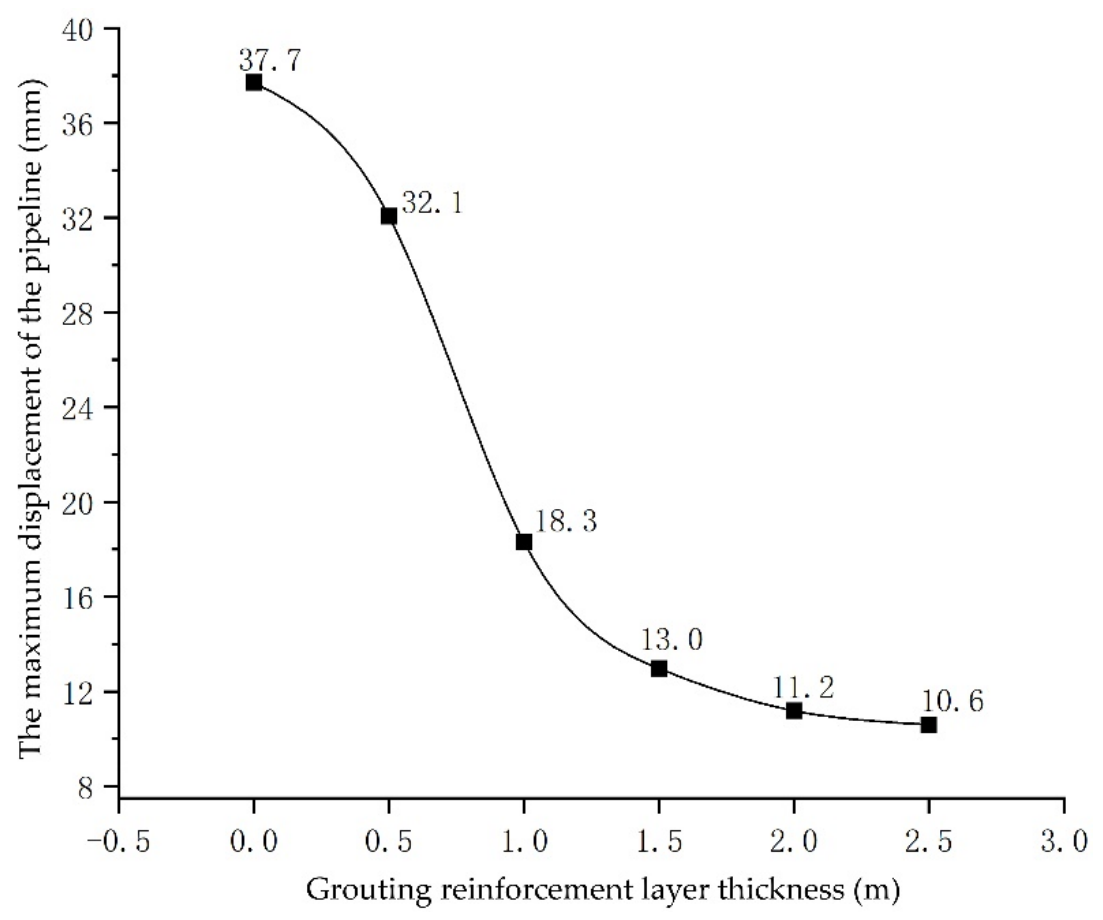

Figure 18. Relationship between the maximum displacement of the pipeline and grouting reinforcement layer thickness.

In conclusion, when the thickness of the grouting reinforcement layer was $h=1.5 \mathrm{~m}$, the reinforcement effect of tunnel surrounding rock was better and the efficiency was higher.

\subsection{Influence of Water-Cement Ratio}

The grouting and solid strength of surrounding rock were related to the uniaxial compressive strength of the rock mass before grouting and the water-cement ratio $\eta$. After the grouting rock mass was determined, the slurry water-cement ratio $\eta$ was the only influencing factor.

\subsubsection{Ground Settlement Analysis}

Figure 19 shows the settlement of each monitoring point on the ground when the water-cement ratio was $0.75,0.80,0.85,0.90,0.95$, and 1.00 . The position corresponding to $\mathrm{x}=0$ was the central axis of the left tunnel, the negative direction was away from the tunnel, and the positive direction was close to the right tunnel. When the water-cement ratio $\eta$ was $0.90,0.95$, and 1.00 , the ground settlement curve was compared. The maximum settlement varied greatly within the range, indicating that the reinforcement effect changed greatly with the increase or decrease of the water-cement ratio $\eta$. When the water-cement ratio $\eta=0.75,0.80$, and 0.85 , the variation range of the maximum settlement was small. When the water-cement ratio varied from 0.75 to 1.00 , the maximum ground settlement continued to increase with the increase of the water-cement ratio, and the increase amplitude gradually becomes larger. The result indicated that when the water cement ratio was high, it had a great influence on the reinforcement effect. 


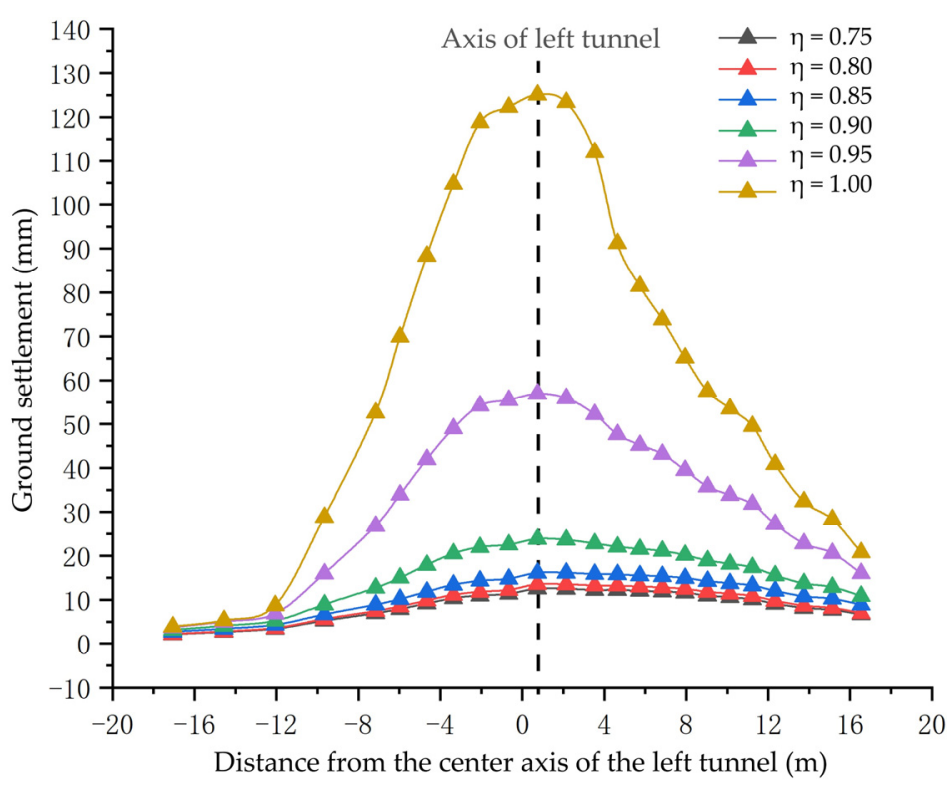

Figure 19. Ground settlement of monitoring points.

Figure 20 shows the relationship between the maximum ground settlement and the slurry water-cement ratio $\eta$. When the slurry water-cement ratio $\eta=0.75,0.80,0.85,0.90$, 0.95 , and 1.00, the maximum surface settlement was $12.5 \mathrm{~mm}, 13.5 \mathrm{~mm}, 16.1 \mathrm{~mm}, 23.8 \mathrm{~mm}$, $56.9 \mathrm{~mm}$, and $125.1 \mathrm{~mm}$, respectively. The variation range of the maximum settlement was $1.0 \mathrm{~mm}, 2.6 \mathrm{~mm}, 7.7 \mathrm{~mm}, 33.1 \mathrm{~mm}$, and $68.2 \mathrm{~mm}$, respectively. The variation range of ground settlement shows that the maximum change in the settlement amount between $\eta=1.00$ and $\eta=0.95$ was the largest, indicating that when the water-cement ratio changed from 0.90 to 1.00 , the reinforcement effect obtained was very significant. When the water-cement ratio $\eta$ changed from 0.75 to 0.80 , the variation range of maximum settlement was only $1.0 \mathrm{~mm}$ and the reinforcement effect was not obvious. In general, when the slurry water cement ratio $\eta=0.90$ or $\eta=0.85$, the maximum ground settlement caused by excavation was small and the reduction was large, the reinforcement effect obtained was better and the benefit was higher.

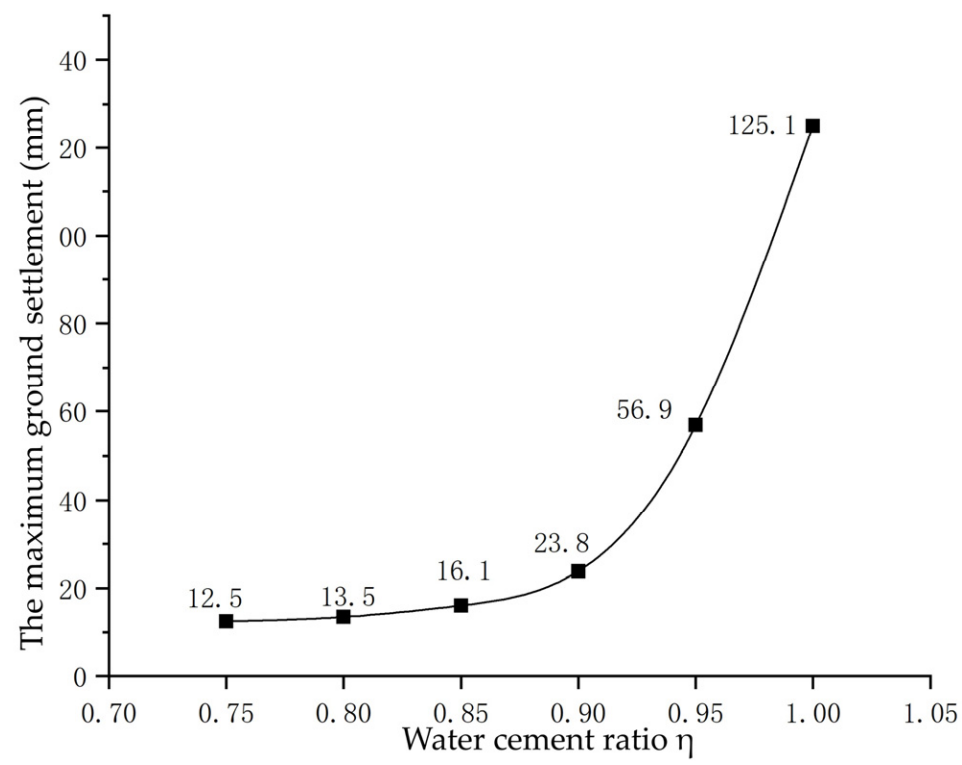

Figure 20. The relationship between the maximum ground settlement and the slurry water-cement ratio $\eta$. 


\subsubsection{Vault Displacement Analysis}

Figure 21 shows the displacement curve of seven monitoring points near the arch crown. Monitoring point 4 was the central point of the vault, monitoring points 1-3 were on the left side of the central point of the vault and monitoring points 5-7 were on the right side of the central point of the vault. When $\eta=0.90,0.95$, and 1.00 , the maximum displacement occurred at the monitoring point 3 , and when $\eta=0.75,0.80,0.85$, the maximum displacement occurred at the center point of the vault, indicating that with the increase of slurry water-cement ratio, the area where the maximum displacement occurred gradually moved to the side of the left partition wall. When the water cement ratio was small $(\eta=0.75,0.80,0.85)$, the displacements of the symmetrical monitoring points with the same height on both sides of the vault were basically the same.

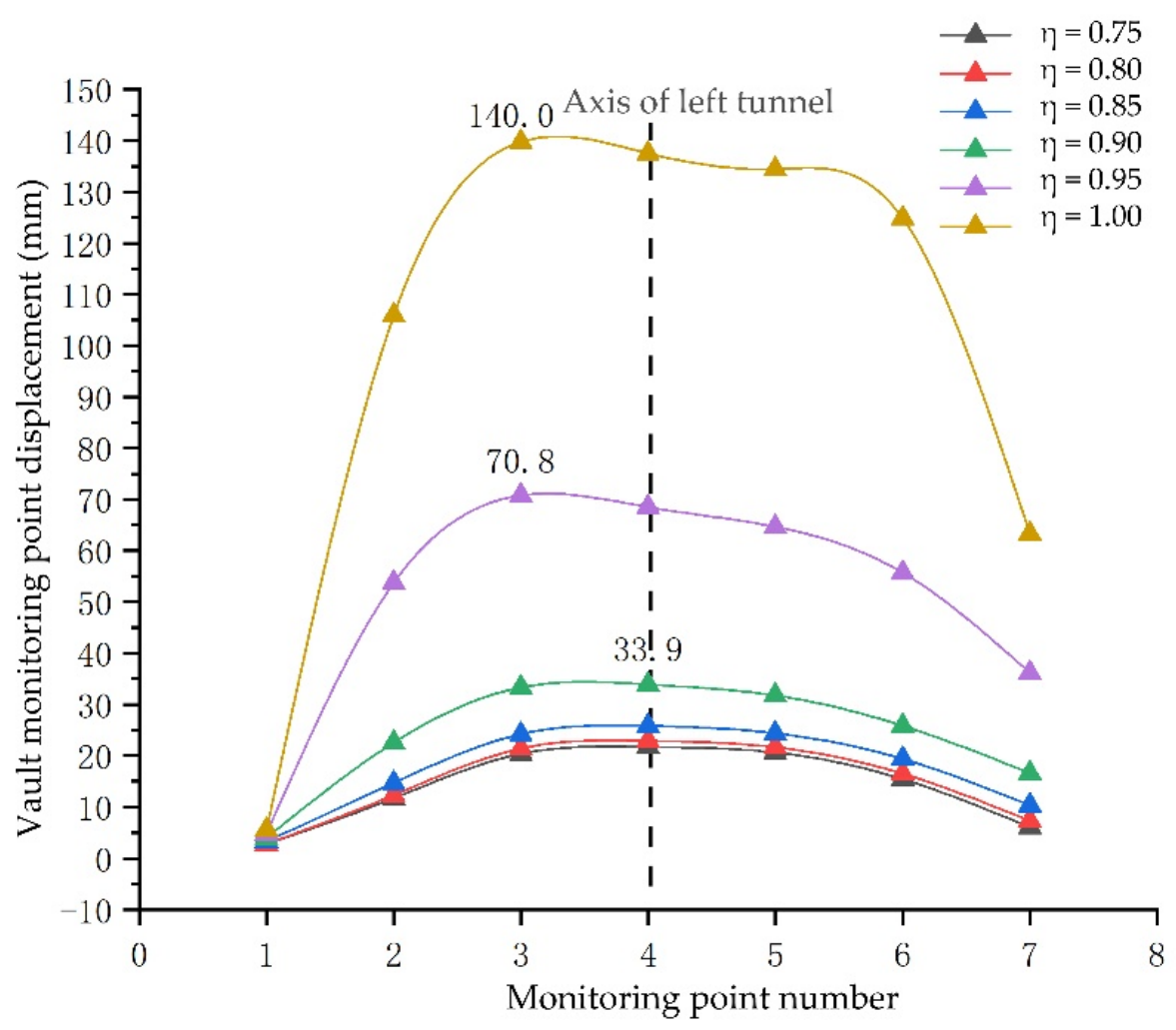

Figure 21. Displacement of monitoring points near the vault of left tunnel.

Figure 22 shows the relationship between the maximum displacement of monitoring points on the vault and the water-cement ratio. When the slurry water-cement ratio $\eta=0.75$, $0.80,0.85,0.90,0.95$, and 1.00 , the maximum displacements of the vault were $21.7 \mathrm{~mm}$, $22.9 \mathrm{~mm}, 25.8 \mathrm{~mm}, 33.9 \mathrm{~mm}, 70.8 \mathrm{~mm}$, and $139.8 \mathrm{~mm}$, respectively. Compared with the simulation results of the previous water-cement ratio condition, the variation range of the maximum displacement of the vault was $1.2 \mathrm{~mm}, 2.9 \mathrm{~mm}, 8.1 \mathrm{~mm}, 36.9 \mathrm{~mm}$, and $69 \mathrm{~mm}$. With the increase of water-cement ratio, the maximum displacement of the vault increased and the increasing range was also increased, indicating that when the water cement ratio was large $(\eta=0.85,0.90,0.95,1.00)$, reducing the slurry water-cement ratio obtained obvious reinforcement effects. When the slurry water-cement ratio was 0.80 or 0.85 , the maximum displacement of vault caused by excavation was small and the reduction range was large, and the reinforcement effect was better and the benefit was higher. 


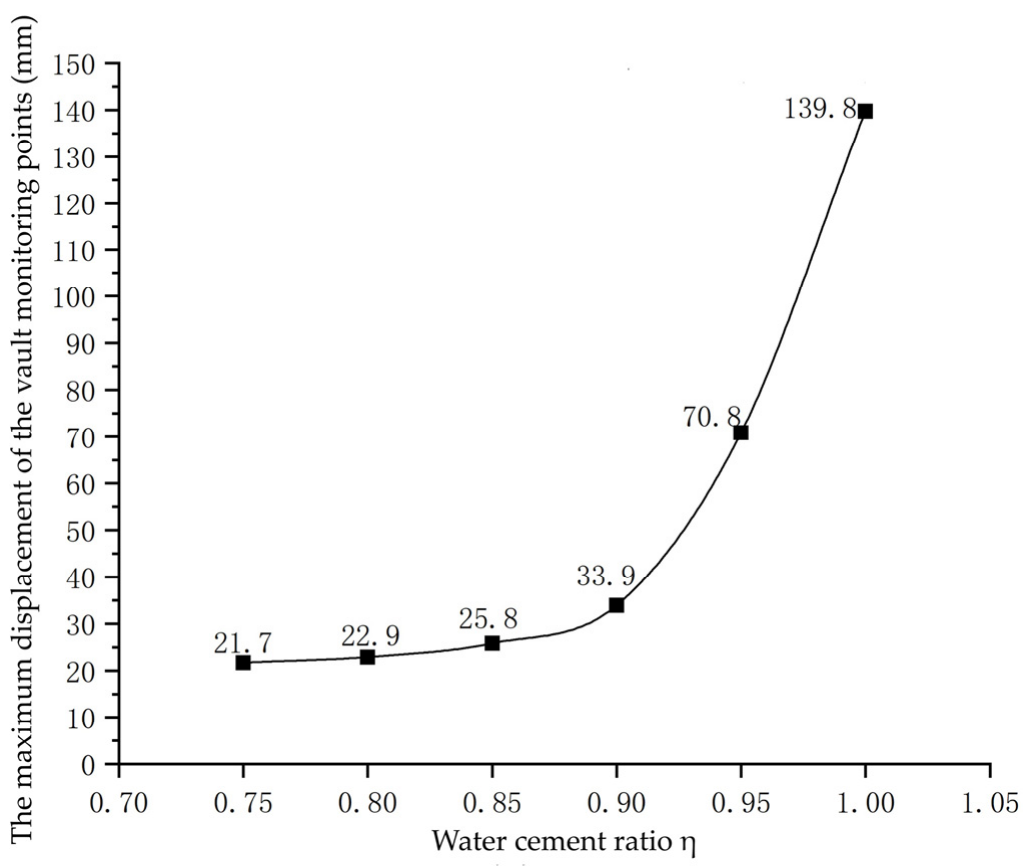

Figure 22. Relationship between the maximum displacement of monitoring points on the vault and water-cement ratio.

\subsubsection{Analysis of Surrounding Rock Plastic Zone}

Table 5 shows the area of shear and tensile plastic zone of surrounding rock with different water-cement ratios $(\eta=0.75,0.80,0.85,0.90,0.95,1.00)$. The ratio of the shear plastic area of grouted surrounding rock $(\eta=0.75,0.80,0.85,0.90,0.95,1.00)$ to the shear plastic area of surrounding rock without grouting was $\omega_{1}$. The ratio of the area of grouted surrounding rock tensile plastic zone to the area of surrounding rock tensile plastic zone without grouting was $\omega_{2}$. When the slurry water-cement ratio $\eta=0.80, \omega_{1}$ and $\omega_{2}$ were 0.37 and 0.15 , respectively. When the slurry water-cement ratio $\eta=0.90, \omega_{1}$ and $\omega_{2}$ were 0.86 and 0.66 , respectively. The variation ranges of the shear plastic zone and tensile plastic zone were $49 \%$ and $51 \%$, respectively. The shear plastic zone area increased with the increase of the slurry water-cement ratio. When the slurry water-cement ratio $\eta=0.75$, the shear plastic zone area reached the minimum $126.17 \mathrm{~m}^{2}$. When the water-cement ratio $\eta$ changed from 0.80 to 0.90 , the area of the shear plastic zone changed greatly $\left(\omega_{1}\right.$ increased from 0.37 to 0.86 ), but when the water-cement ratio changed in other ranges, the shear plastic zone area changed little. The area of the tensile plastic zone increased with the increase of the water cement ratio. The singularity was that when $\eta=0.95$, the area of the tensile plastic zone was $277.55 \mathrm{~m}^{2}$, which was larger than the area obtained in the two adjacent working conditions. The smaller the water-cement ratio, the better the grouting reinforcement effect, the better the self-supporting capacity, and the lower the possibility of yield failure.

Table 5. Shear and tensile plastic zone area of surrounding rock under different water-cement ratios.

\begin{tabular}{ccccccc}
\hline $\begin{array}{c}\text { Grouting Reinforcement } \\
\text { Layer Thickness }\end{array}$ & $\boldsymbol{\eta}=\mathbf{0 . 7 5}$ & $\boldsymbol{\eta}=\mathbf{0 . 8 0}$ & $\boldsymbol{\eta}=\mathbf{0 . 8 5}$ & $\boldsymbol{\eta}=\mathbf{0 . 9 0}$ & $\boldsymbol{\eta}=\mathbf{0 . 9 5}$ & $\boldsymbol{\eta}=\mathbf{1 . 0 0}$ \\
\hline Shear plastic zone area $\left(\mathrm{m}^{2}\right)$ & 126.17 & 142.21 & 245.67 & 332.10 & 338.17 & 360.69 \\
$\omega_{1}$ & 0.33 & 0.37 & 0.64 & 0.86 & 0.88 & 0.94 \\
Tensile plastic zone area $\left(\mathrm{m}^{2}\right)$ & 22.41 & 44.02 & 113.13 & 188.00 & 277.55 & 248.25 \\
$\omega_{2}$ & 0.08 & 0.15 & 0.40 & 0.66 & 0.97 & 0.87 \\
\hline
\end{tabular}




\subsubsection{Pipeline Deformation Analysis}

Figure 23 shows the deformation of the pipeline. With the increasing distance from the middle partition wall, the pipeline deformation first increased and then decreased, and the pipeline deformation reached the maximum near the central axis of the left tunnel. When the distance from the partition wall was greater than $21 \mathrm{~m}$, the deformation of the pipeline was small and the deformation was basically stable. The slurry water-cement ratio had a great influence on the deformation of the pipeline. The deformation of the pipeline increased with the increase of the slurry water-cement ratio, and the increasing range also gradually increased.

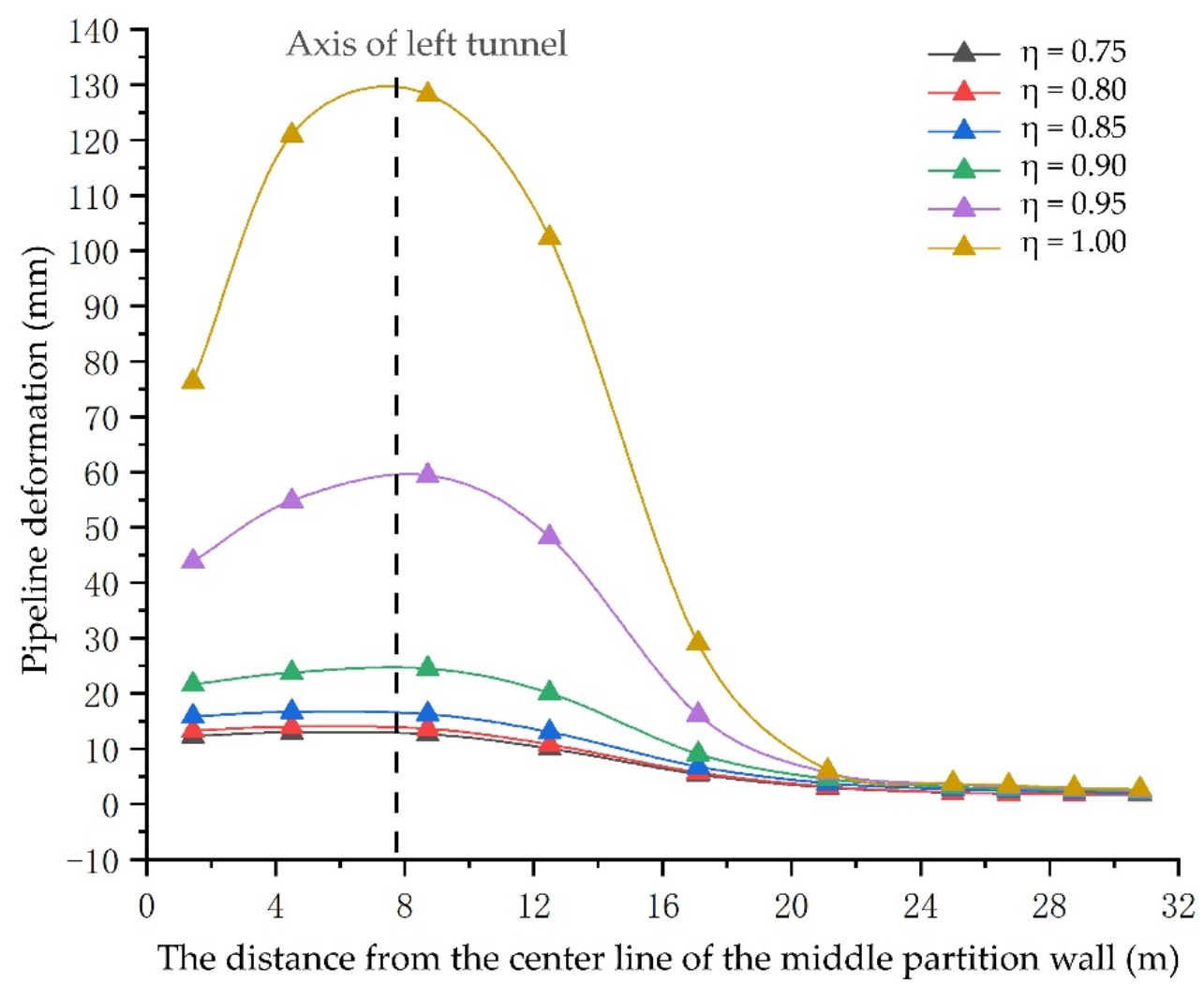

Figure 23. Pipeline deformation.

Figure 24 shows the relationship between the maximum displacement of pipeline and water-cement ratio $\eta$. When the slurry water-cement ratio $\eta=0.75,0.80,0.85,0.90,0.95$, and 1.00 , the maximum displacement of the pipeline was $13.0 \mathrm{~mm}, 14.0 \mathrm{~mm}, 16.6 \mathrm{~mm}, 24.5 \mathrm{~mm}$, $59.4 \mathrm{~mm}$, and $128.2 \mathrm{~mm}$, respectively. Compared with the results of the previous slurry water-cement ratio, the variation amplitude of the maximum displacement of the pipeline was $1 \mathrm{~mm}, 2.6 \mathrm{~mm}, 7.9 \mathrm{~mm}, 34.9 \mathrm{~mm}$, and $68.8 \mathrm{~mm}$. With the increase of water-cement ratio, the maximum displacement of the pipeline increased gradually, and the increasing amplitude also increased. When $\eta=0.85$ and $\eta=0.90$, the maximum displacement of the pipeline was small and the variation amplitude was large, indicating that the effect of grouting reinforcement was good.

According to the analysis, when the slurry water-cement ratio $\eta=0.85$ in actual engineering, the tunnel surrounding rock reinforcement effect was better and more economical. 


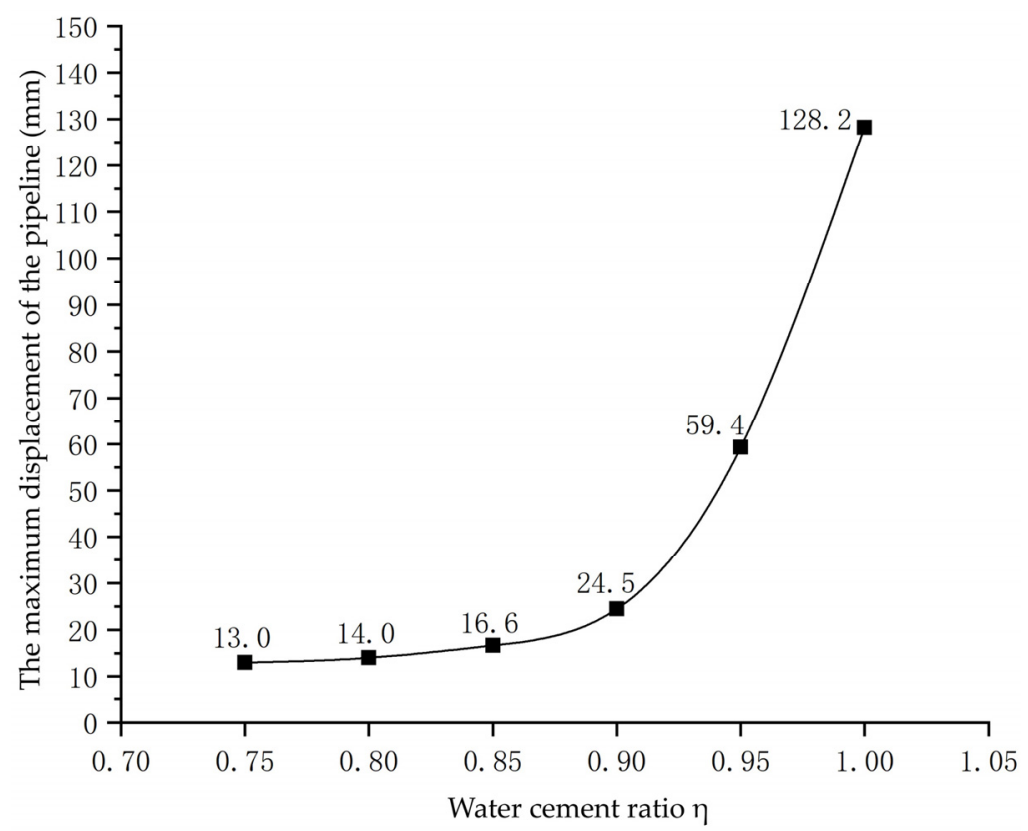

Figure 24. Relationship between the maximum displacement of pipeline and water-cement ratio $\eta$.

\section{Conclusions}

To study the reasonable grouting thickness and water-cement ratio of the surrounding rock of the double arch tunnel in the Haicang Tunnel, the ground settlement, deformation of the vault, and adjacent pipeline under different grouting parameters were studied through laboratory tests, literature analysis, and numerical simulation. The following conclusions were obtained.

(1) The viscosity of cement slurry decreased with the increase of water-cement ratio. The initial setting time of cement slurry increased linearly with the increasing water-cement ratio. The slurry bleeding rate gradually increased with time and tended to be stable after reaching a certain value, and the greater the water-cement ratio, the greater the slurry bleeding rate. The strength of the sample decreased linearly with the increase of the water cement ratio.

(2) Frictional angle $\varphi$ and cohesive force $\mathrm{c}$ can be determined by water-cement ratio of slurry and UCS of rock mass before grouting.

(3) With the increase of reinforcement layer thickness and the decrease of cement slurry water-cement ratio, the ground settlement, vault displacement, plastic zone area, and pipeline deformation continued to decrease, but the reduction range increased first and then decreased.

(4) When the grouting reinforcement layer thickness $\mathrm{h}=1.5 \mathrm{~m}$ and the water-cement ratio $\eta=0.85$, the tunnel grouting reinforcement effect was best and more economical.

Author Contributions: J.W.: conceptualization, funding acquisition, writing —original draft, writingrevision; A.C.: writing-original draft; Z.W.: software; H.W.: funding acquisition; X.L., H.L. and Y.S.: validation. All authors have read and agreed to the published version of the manuscript.

Funding: This research was funded by the Shanghai Municipal Science and Technology Project (18DZ1201301; 19DZ1200900); Xiamen Road and Bridge Group (XM2017-TZ0151; XM2017-TZ0117); the project of Key Laboratory of Impact and Safety Engineering (Ningbo University), Ministry of Education (CJ202101); Shanghai Municipal Science and Technology Major Project (2021SHZDZX0100) and the Fundamental Research Funds for the Central Universities; Key Laboratory of Land Subsidence Monitoring and Prevention, Ministry of Natural Resources of the People's Republic of China (No. KLLSMP202101), Suzhou Rail Transit Line 1 Co. Ltd., China Railway 15 Bureau Group Co. 1td.

Data Availability Statement: The data presented in this study are available on request from the corresponding author. 
Conflicts of Interest: The authors declare no conflict of interest.

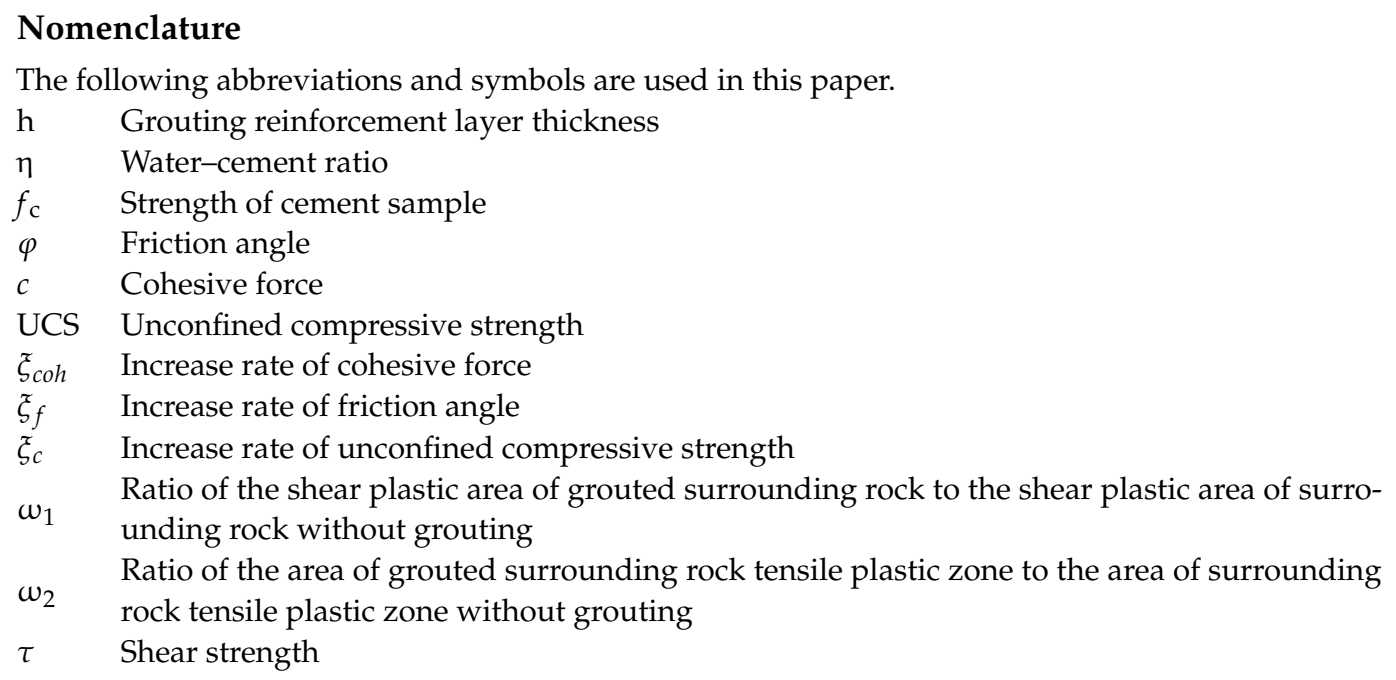

\section{References}

1. Xu, Z.; Wang, B.; Kong, J.; Chen, T.; Liang, Y. Study on the influence of ceiling tunnel angle on the gas shunting efficiency of urban highway tunnel. Case Stud. Therm. Eng. 2021, 25, 100888. [CrossRef]

2. Wang, Y.; Zhao, Y.; Li, Y.Y.; Ge, X.Y.; Wang, S.H. Risk evaluating of chongqing yangtze river highway tunnel environment. IOP Conf. Ser. Earth Environ. Sci. 2020, 526, 012021. [CrossRef]

3. Yang, H.; Liu, C.; Jiang, X.; Shi, H.; Sun, G. Shaking table test and numerical simulation for dynamic response of shallow-buried bias double-arch tunnel. Geotech. Geol. Eng. 2020, 38, 3915-3929. [CrossRef]

4. Vosoughifar, H.; Madadi, F.; Rabiefar, A. Modified dynamic stress concentration factor for twin tunnels using a novel approach of FEM-scattering. Tunn. Undergr. Space Technol. 2017, 70, 30-41. [CrossRef]

5. Wang, S.R.; Wang, Y.G.; Li, C.L.; Zou, Z.S.; Cui, F. Evolution characteristics analysis of pressure-Arch of a highway tunnel under different stress conditions. J. Eng. Sci. Technol. Rev. 2016, 9, 99-105. [CrossRef]

6. Wang, H.N.; Zeng, G.S.; Sutilt, S.; Jiang, M.G.; Wu, L. Analytical solutions of stresses and displacements for deeply buried twin tunnels in viscoelastic rock. Int. J. Rock Meck. Min. 2017, 93, 13-29. [CrossRef]

7. Li, C.; Wang, S.; Wang, Y. Skewed pressure characteristics of equivalent load in double-arch tunnel. J. Geophys. Eng. 2016, 48, 345-358. [CrossRef]

8. Zhu, Y.T.; Zhang, H.; Zhang, Z.X.; Liu, K. Physical model test study of influence of advance of shield tunnel on adjacent underground pipelines. Rock Soil Mech. 2016, 37, 151-160. [CrossRef]

9. Wang, H.; Wu, Y.; Hui, J.; Jia, J.Q.; Wang, K. Field measurement and numerical simulation of the influence of blasting excavation on adjacent buried pipelines. Int. J. Crit. Infrastruct. 2019, 15, 70-89. [CrossRef]

10. Zang, C.; Chen, M.; Zhang, G.; Wang, K.; Gu, D. Research on the failure process and stability control technology in a deep roadway: Numerical simulation and field test. Energy Sci. Eng. 2020, 8, 2297-2310. [CrossRef]

11. Huang, F.; Zhang, M.; Wang, F.; Ling, T.; Yang, X. The failure mechanism of surrounding rock around an existing shield tunnel induced by an adjacent excavation. Comput. Geotech. 2020, 117, 103236. [CrossRef]

12. Shin, J.H.; Choi, Y.K.; Kwon, O.Y.; Lee, S.D. Model testing for pipe-reinforced tunnel heading in a granular soil. Tunn. Undergr. Space Technol. 2008, 23, 241-250. [CrossRef]

13. Sun, L.; Jiang, Z.; Liu, B. Numerical simulation and analysis of advance pre-support for underground cross-street tunnel. IOP Conf. Ser. Earth Environ. Sci. 2019, 267, 042007. [CrossRef]

14. Niu, J.; Li, Z.; Gu, W.H.; Chen, K. Experimental study of split grouting reinforcement mechanism in filling medium and effect evaluation. Sensors 2020, 20, 3088. [CrossRef]

15. Zhu, M.; Zhang, Q.; Li, S.C.; Liu, R.; Zhang, L. Numerical simulation and experimental study on soil split grouting reinforcement mechanism. J. Cent. South Univ. 2018, 49, 1213-1220.

16. Lan, X.; Zhang, X.; Li, X.; Zhang, J.; Zhou, Z. Experimental study on grouting reinforcement mechanism of heterogeneous fractured rock and soil mass. Geotech. Geol. Eng. 2020, 38, 4949-4967. [CrossRef]

17. Jin, P. Bridge and tunnel engineering construction strengthening technology of grouting method in application. In Proceedings of the International Conference on Electronic, Shenyang, China, 1-3 April 2016.

18. $\mathrm{Wu}, \mathrm{K} . ; \mathrm{Ma}, \mathrm{M} . \mathrm{Y}$. Evaluation of the grouting effect of the change of grout hole spacing in splitting grouting for dams. App. Mech. Mater. 2012, 151, 295-299. [CrossRef]

19. Wang, H.; Zhang, Q.; Liu, R.; Li, S.; Zhang, L.; Liu, Y.; Gui, D. Grouting reinforcement mechanism and experimental study of cement quick-setting slurry infiltration. IOP Conf. 2017, 81, 012025. [CrossRef] 
20. Huang, M.; Zou, C.; Meng, Z.H. The influence of different grouting methods on the surface environment of short clear distance tunnel. IOP Conf. Ser. Earth Environ. Sci. 2020, 510, 052063. [CrossRef]

21. Yi, W.; Wang, Y.H.; Zhou, R. Application of grouting technology. Adv. Mater. Res. 2011, 163-167, 471-474. [CrossRef]

22. Zong, Y.J.; Han, L.J.; Han, G.L. Study on shear properties of rock structural plane by grouting reinforcement. Adv. Mater. Res. 2011, 250-253, 1520-1526. [CrossRef]

23. Heo, H.S.; Lee, B.J. Study on durability of grouting materials for reinforcement in a double-deck tunnel. Int. J. Eng. Technol. 2018, 10, 294-299. [CrossRef]

24. Evdokimov, P.D.; Adamovich, A.N.; Fradkin, L.P.; Denisov, V.N. Shear strengths of fissures in ledge rock before and after grouting. Hydrotech. Constr. 1970, 4, 229-233. [CrossRef]

25. Moosavi, M.; Bawden, W.F. Shear strength of portland cement grout. Cem. Concr. Compos. 2003, 25, 729-735. [CrossRef]

26. Cheng, H.; Peng, S.L.; Rong, C.X.; Sun, Z.H. Numerical simulation and engineering application of grouting reinforcement for surrounding rocks of chamber in deep of $1000 \mathrm{~m}$ by L-shaped boreholes. Yantu Lixue Rock Soil Mech. 2018, 39, 274-284. [CrossRef]

27. Lu, Y.F.; Yu, Y.Y.; Chen, Z.M. Study on grouting reinforcement of surrounding rock of tunnel under railway station. In Proceedings of the 2020 12th International Conference on Measuring Technology and Mechatronics Automation (ICMTMA), Phuket, Thailand, 28-29 February 2020.

28. Yang, L.; Lin, R.F.; Li, Z.F.; Li, S.C.; Zhang, Q.S.; Liu, R.T.; Zhang, X.; Wang, K.; Chen, H. Influence of grout viscosity on the grouting reinforcement effect of completely weathered granite. China J. Highw. Transp. 2018, 31, 246-254.

29. Liu, B.; Sang, H.; Wang, Z. Experimental study on the mechanical properties of rock fracture after grouting reinforcement. Energies 2020, 13, 4814. [CrossRef]

30. Ma, S.J.; Ma, D.P. Grouting material for broken surrounding rock and its mechanical properties of grouting reinforcement. Geotech. Geol. Eng. 2021, 39, 3785-3793. [CrossRef]

31. Li, Z.; Zhang, L.; Chu, Y.T.; Zhang, Q.S. Research on influence of water-cement ratio on reinforcement effect for permeation grouting in sand layer. Adv. Mater. Sci. Eng. 2020, 2020 (Suppl. 1), 5329627. [CrossRef]

32. Wang, Z.; Long, L.I.; Wang, C. Experimental study on failure of cracked rock-like material after grouting reinforcement. J. Cent. South Univ. 2018, 49, 957-963. [CrossRef]

33. National Standards of the People's Republic of China. Standard for Test Methods of Concrete Physical and Mechanical Properties (GB/T50081-2019); China Architecture and Architecture Press: Beijing, China, 2019.

34. Zhan, X.D. Experimental research of grouting reinforcement mechanism for broken rock soil mass as heterogeneous medium. Munic. Eng. Technol. 2019, 2, 113-116.

35. Zong, Y.J.; Han, L.J.; Han, G.L. Mechanical characteristics of confined grouting reinforcement for cracked rock mass. J. Min. Saf. Eng. 2013, 4, 483-488.

36. Wang, H.P.; Gao, Y.F.; Li, S.C. Uniaxial experiment study on mechanical properties of reinforced broken rocks pre-and-post grouting. Chin. J. Undergr. Space Eng. 2007, 3, 27-31.

37. Zhou, W.Y.; Yang, R.Q.; Yan, G.R. Study on the efficacy of grouting reinforcement of slightly weathered rock masses at the ertan arch dam abutments. Chin. J. Rock Mech. Eng. 1993, 12, 138-150.

38. Liu, C.W.; Lu, S.L. Reinforcement effect of cement grouting on engineering rock mass. J. China Univ. Min. Technol. 2000, 29, 454-458.

39. Yang, M.J.; Zhang, N. Study on the intrinsic model of broken rockmass after grouting reinforcement. Met. Mine 1998, 5, 11-14.

40. Niu, X.L.; Fu, Z.L. Test of grouting reinforcement of deep roadway and control of its stability. Met. Mine 2007, 37, 18-21.

41. Xu, H.F.; Geng, H.S.; Li, C.F.; Chen, W.; Wang, C. Estimating strength of grouting reinforced bodies in broken rock mass. Chin. J. Geotech. Eng. 2013, 11, 2018-2022. 